\title{
Detection of High Energy Particles Using CR-39 Detectors Part 1: Results of Microscopic Examination, Scanning, and LET Analysis
}

\author{
P.A. Mosier-Boss ${ }^{1}$ \\ GEC \\ 5101B Backlick Rd. \\ Annandale, VA 22003 \\ USA \\ F.E. Gordon \\ Navy Senior Executive Service (retired) \\ San Diego, CA 92122 \\ USA \\ L.P. Forsley \\ JWK International Corp. \\ Annandale, VA 22003 \\ USA \\ Dazhuang Zhou ${ }^{2}$ \\ China \\ Work conducted while with
}

National Space Science Center, Chinese Academy of Sciences, Beijing 100190, Republic of

NASA-Johnson Space Center, 2101 Nasa Parkway, Houston, TX 77058, USA

Universities Space Research Association, 3600 Bay Area Blvd, Houston, TX 77058, USA

\begin{abstract}
CR-39 detectors were used to detect high energy particles produced during $\mathrm{Pd} / \mathrm{D}$ co-deposition. Upon completion of the experiments, the detectors were subjected to either microscopic examination, scanning using an automated scanner to obtain quantitative information on the tracks, sequential etching, or linear energy transfer (LET) spectrum analysis. Both the sequential etching and LET analysis allowed speciation of the particles that caused the tracks as well as estimating their energies. In these experiments it was shown that the tracks coincide with the placement of the Pd deposit. The average number of tracks obtained as a result of

\footnotetext{
${ }^{1}$ Corresponding author: pboss@ san.rr.com ; (858) 576-6415

${ }^{2}$ Corresponding author on LET analysis: dazhuang.zhou@gmail.com; zhou_dazhuang@ 163.com; (281) 244-6196
} 
$\mathrm{Pd} / \mathrm{D}$ co-deposition is more than 133 times greater than that found in the background. In this communication, the results of microscopic examination, scanning, and LET analysis are discussed.

KEYWORDS: palladium; nuclear particles; CR-39; LET spectrum; energy distribution

\subsection{INTRODUCTION}

Recently Holmlid and Olafsson [1] reported the detection of high energy particles from spontaneous processes occurring in an ultra-dense deuterium $\mathrm{D}(0)$ layer. They also speculated that low energy nuclear reactions (LENR) may also give rise to such particles. Consequently, any experiments that show the emission of energetic particles would support this supposition. There have been previous reports of tritium [2-17], neutrons [8, 9, 13, 14, 18-28], charged particles [2931], and helium-4 [32-36] generated electrochemically using either Pd or Ti cathodes. A review of nuclear products generated as a result of LENR experiments [37] summarizes the nuclear products that have been detected using various methods in both electrolytic and gas loading experiments. Of the nuclear products generated, only helium-4 correlated with the production of excess heat [35]. The nature of the reactions that have produced these energetic particles is not fully understood. The particles observed and their energies are consistent with DD primary and secondary reactions. What is known is that, in order to induce the effect, the deuterium needs to be contained within a metal lattice, the $\mathrm{D} / \mathrm{Pd}$ loading is $\geq 0.9$, and that there is deuterium flux inside the lattice. Enhancements in DD reactions in metal lattices have been observed in accelerator experiments $[38,39]$. The observed enhancements in the reaction was larger than the theoretically calculated Gamow Factor, indicating that electron screening plays a significant role in increasing fusion rates at low energies. However, the observed cross section enhancements observed in these accelerator experiments was significantly larger than could be accounted for by electron screening alone [40]. These observations suggest that there is an additional mechanism of the screening that enables deuteria to tunnel through the Coulomb barrier.

The emission of energetic charged particles during Pd/D co-deposition has been reported [41]. To detect these high energy particles, the solid state nuclear track detector (SSNTD), CR- 
39 was used [42]. CR-39, an allyl diglycol carbonate with a chemical composition of $\mathrm{C}_{12} \mathrm{H}_{18} \mathrm{O}_{7}$, is sensitive to charged particles with high LET ( $\geq 3 \mathrm{keV} / \mu \mathrm{m}$ CR-39). When low energy protons, heavy charged particles, fast protons or secondary heavy charged particles from neutron recoils traverse CR-39, they break the polymer molecular bonds forming highly reactive paths along their trajectories. These paths can be revealed as cones on the surfaces of the detectors after chemical etching. The optical properties of the tracks resulting from $\mathrm{Pd} / \mathrm{D}$ co-deposition were consistent with those of nuclear generated tracks [43]. A series of control experiments showed that the tracks were not due to radioactive contamination of the cell components nor were they the result of either chemical or mechanical damage. This experiment has been very reproducible. We have done close to fifty experiments using different substrates to plate on, with and without external fields, as well as different cell configurations [41, 43, 44] and have gotten the same results. These experiments were replicated by three groups of senior chemical engineering undergraduates at the University of California San Diego [45].

In this effort, $\mathrm{Pd} / \mathrm{D}$ co-deposition experiments were conducted at SRI with the CR-39 detectors inside the cell in contact with the cathode and outside the cell. The detectors used in the immersion experiments were designated 10-5 and 10-6. In the outside the cell experiments, the CR-39 detector and cathode were separated by a $6 \mu \mathrm{m}$ thick Mylar film. This detector was designated 10-7. Upon completion of the experiments, the etched CR-39 detectors were analyzed independently by us and a group led by the Lebedev Physics Institute (LPI). Our group subjected detectors 10-5 and 10-6 to microscopic examination, scanning using an automated scanner, and linear energy transfer (LET) spectrum analysis while the LPI led group subjected detectors 10-5 and 10-7 to sequential etching analysis. The purpose of the LET spectrum analysis and the sequential etching analysis was to speciate and determine the energies of the high energy particles that were generated as a result of $\mathrm{Pd} / \mathrm{D}$ co-deposition. In this communication, the results of the microscopic examination, scanning, and LET spectrum analysis of detectors 10-5 and 10-6 are discussed. Sequential etching analysis of detectors 10-5 and 10-7 are discussed in the second communiqué. As will be shown, the two disparate methods of analyzing the detectors yield similar results. 


\subsection{EXPERIMENTAL}

\subsection{Materials}

Palladium chloride (Aldrich), lithium chloride (Mallinckrodt), deuterated water (Aldrich), HPLC grade light water (Aldrich), sodium hydroxide (Aldrich), copper chloride (Aldrich), 0.25 $\mathrm{mm}$ diameter silver wire, $0.5 \mathrm{~mm}$ diameter silver wire (Aldrich), and $0.25 \mathrm{~mm}$ diameter platinum wire (Aldrich) were used as received. CR-39 detectors (Fukuvi), rectangular in shape with dimensions of $1 \mathrm{~cm} \times 2 \mathrm{~cm} \times 1 \mathrm{~mm}$, were obtained from Landauer and used as received.

\subsection{Cell Design and Charging Procedure}

A schematic of the rectangular, butyrate cell in Figure 1a shows the orientation of the anode, cathode, and NdFeB magnets employed in the experiments done at SRI using detectors 10-5 and 10-6. The strength of the magnetic field was 2500 Gauss. The magnetic field was present throughout the course of the experiment. Previous experiments done by us and others $[46,47]$ have shown that the presence of an external magnetic field results in increased heat production. This suggests that a magnetic field enhances the effect.

A schematic of the cathode is shown in Figure 1b. The cathode consists of a single $16 \mathrm{~cm}$ long, $0.25 \mathrm{~mm}$ diameter Ag wire wrapped serpentine around a CR-39 detector (Fukuvi) as shown in Figure 1b. Of this, $\sim 4.2 \mathrm{~cm}$ of the wire was in contact with the plating solution. The exposed surface area of this $\mathrm{Ag}$ wire was $0.33 \mathrm{~cm}^{2}$. A $60 \mu \mathrm{m}$ thick polyethylene film separated the cathode from the CR-39 detector. This film protected the surface of the detector from mechanical and chemical damage. A solution of $0.03 \mathrm{M} \mathrm{PdCl}_{2}$ and $\mathrm{LiCl}$ in $\mathrm{D}_{2} \mathrm{O}$ was added and $\mathrm{Pd}$ was plated out onto the Ag wire. The charging profile was $0.2 \mathrm{~mA}$ for one day followed by $0.5 \mathrm{~mA}$ until the solution cleared. This assured good adherence of the Pd onto the Ag wire. Once plated out, the cathodic current was increased, in a stepwise fashion, to $1 \mathrm{~mA}$ for $48 \mathrm{~h}, 5 \mathrm{~mA}$ for $20 \mathrm{~h}, 10 \mathrm{~mA}$ for $28 \mathrm{~h}, 25 \mathrm{~mA}$ for $60 \mathrm{hr}$, and $100 \mathrm{~mA}$ for $36 \mathrm{~h}$. The surface area of the electrode is estimated to increase by approximately a factor of $10 x$ after $\mathrm{Pd}$ deposition has completed.

A control experiment using $\mathrm{CuCl}_{2}$ in place of $\mathrm{PdCl}_{2}$ was done by the authors. The SRI protocol was followed in the control experiment. Specifically, a $60 \mu \mathrm{m}$ thick polyethylene film separated the cathode from the CR-39 detector and a magnetic field was present throughout the 
course of the experiment. The current-time profile described above was used once all the copper had plated out.

\subsection{Etching, Microscopic Examination, and Scanning of CR-39 Detectors}

At the end of each experiment, the polyethylene film was removed and the CR-39 detector was etched in $6.5 \mathrm{~N} \mathrm{NaOH}$ at $65^{\circ} \mathrm{C}$ for $7 \mathrm{~h}$. Microscopic examination of the etched CR-39 detectors was done using an Eclipse E600 epifluorescent microscope (Nikon) and CoolSnap HQ CCD camera (Photometrics). Magnifications of 200X and 1000X were used. The software used to obtain the images was MetaVue (MDS Analytical Technologies).

Scanning of the CR-39 detectors was done using a TASL Image system (Track Analysis Systems, Ltd, Bristol, UK) to obtain quantitative information on the pits produced in the CR-39. The system has a high quality microscope optical system (Nikon cfi series) operating at a magnification high enough to discriminate between tracks and background. The images obtained were then analyzed by the proprietary software. The software makes 15 characteristic measurements of each feature located in the image to provide reliable discrimination between etched tracks and background features present on or in the plastic detectors. These measurements include track length and diameter, optical density (average image contrast) and image symmetry. Based upon the measured properties of a feature, the software of the automated scanning system determines whether or not the measured features are consistent with that of an energetic particle. The software algorithms ignore overlapping tracks. The scanned data for both detectors are provided in the supplementary material.

\subsection{LET Analysis of CR-39 Detectors}

In CR-39, the linear stopping power, $(\mathrm{dE} / \mathrm{dx})_{\mathrm{elec}}$, contributed by atomic collisions of charged particles, where 'elec' specifies electronic (atomic collision), is related to the restricted energy loss (LET). The LET is defined as $\mathrm{L}_{\Delta}=\mathrm{dE}_{\Delta} / \mathrm{dx}$, where $\mathrm{dE}_{\Delta}$ is the energy loss by a charged particle due to electronic collision, minus the sum of the kinetic energies of all the electrons released with kinetic energies in excess of $\Delta$. For CR-39, electrons with energies greater than $\Delta=200 \mathrm{eV}$ don't form tracks. The restricted energy loss is often written as $\mathrm{LET}_{\Delta}$ and the 
unrestricted energy loss as LET $\infty$. The $\mathrm{LET}_{\Delta}$ for the $\Delta=200 \mathrm{eV}$ is often noted as LET 200 . The LET

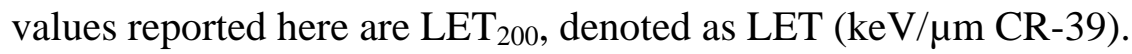

As indicated vide supra, there is a preferential, or faster etch, along the direction of a particle's trajectory where the polymer has been damaged by the energy deposited. The chemical etching forms cones on the surface of CR-39 detector that are observable with an optical microscope. In order to determine the bulk etch rate, the thickness and the mass before and after etch for the CR-39 plate were measured and the bulk etch B, the thickness etched off on one surface of the CR-39 detector, was calculated by Henke's formula [48]:

$$
B=\frac{\left(m_{1}-m_{2}\right) T_{2}}{2 m_{2}}\left(1-\frac{p T_{2}}{2 A_{d}}\right)
$$

where $\mathrm{m}_{1}$ is the detector mass before etch, $\mathrm{m}_{2}$, the mass after etch; $\mathrm{T}_{2}$, the average detector thickness after etch; $\mathrm{p}$, the detector perimeter and $\mathrm{A}_{\mathrm{d}}$, the detector surface area.

The etch rate ratio is defined as $S=V_{T} / V_{B}$, where $V_{B}$ is the etch rate of the undamaged regions of the detector (bulk etch rate) and $\mathrm{V}_{\mathrm{T}}$ is the track etch rate defined as $\mathrm{V}_{\mathrm{T}}=\mathrm{L}_{\mathrm{o}} / \mathrm{t}$, where $\mathrm{L}_{\mathrm{o}}$ is the length from pre-etch surface to the etched cone tip measured along the particle's trajectory and $t$ is the etch time. The etch rate ratio can be calculated with Somogyi's formula if the etched cone is conical [49]:

$$
S=\sqrt{\left.1+4\left(\frac{a}{2 B}\right)^{2} / 1-\left(\frac{b}{2 B}\right)^{2}\right]^{2}}
$$

where $\mathrm{a}$ and $\mathrm{b}$ are the major and minor axes of the etched cones respectively that are measured during the automatic scanning. LET values for measured charged-particles can be calculated using LET calibration for CR-39 detectors.

The relationship between LET $_{200}$ in CR-39 and the etch rate ratio S was determined by calibrating CR-39 detectors using heavy ions and protons with different energies generated by different accelerator centers for CR-39 manufactured by American Technical Plastics [50]. The LET $_{200}$ CR-39 values of calibration particles can be calculated either by Benton table [51] or by computer codes [52] and, S values can be calculated with Somogyi formula. Although CR-39 material manufactured by different companies etches differently as a function of the 
manufacturing processes, the LET calibrations are based upon the CR-39 chemical formula and are essentially identical. The research work using CR-39 detectors in DIAS (Dublin Institute for Advanced Studies, Ireland), NASA-JSC (Johnson Space Center) and NSSC (National Space

Science Center, Chinese Academy of Sciences) has shown that the LET calibrations for CR-39 are consistent and independent of manufacturing due to the identical CR-39 chemical components. Therefore, the LET American Technical Plastic CR-39 calibration [50] was used for the Fukuvi CR-39 employed here.

For each track, or scanned event, the etch rate ratio was calculated, using the major and minor axes measured for each track, and the LET value was determined and binned, then the differential fluence spectrum was generated. The differential fluence for the particles recorded can be expressed as

$$
\mathrm{f}=\mathrm{dN}(\mathrm{i}) /\left[\mathrm{A}_{\mathrm{S}} \times \mathrm{dLET}(\mathrm{i})\right]
$$

where $A_{S}$ is the scanned area of CR-39 detector, $\mathrm{dN}(\mathrm{i})$ is the number of particles in the ith LET bin LET(i) with a bin width of dLET(i). The net differential fluence for LENR particles is obtained by subtracting the background (radon $\alpha$ particles, ground cosmic rays, and defects of CR-39 material) from the total differential fluence. However, as will be shown vide infra, the LENR background is low and can be ignored. The integral spectrum of fluence is generated by summing the differential spectrum from high LET to low LET. In the LET method of analysis for CR-39 detectors, the error in the LET calculations is mainly due to the measurement errors of the dimensions of the detector and the track cone surfaces. For the mass difference method used for the bulk etch calculation, the relative error of the bulk etch is $<\sim 1 \%$. If the automatic data scan is used, as was done in these analyses, the relative error for the dimensions of the track cone surface is also $<\sim 1 \%$. Therefore, the error of the LET calculations resulting from the measurements can be ignored. Additional details on the LET spectrum method using CR-39 detectors and its applications can be found in references [53-61].

\subsection{RESULTS AND DISCUSSION}

\subsection{Microscopic Examination of the CR-39 Detectors}

The Fukuvi CR-39 detectors come covered on both sides with a $60 \mu \mathrm{m}$ thick polyethylene film. In the SRI replication, this film was between the cathode and the detector. Linear energy 
transfer (LET) calculations [62] indicate that $60 \mu \mathrm{m}$ thick polyethylene will block $7 \mathrm{MeV}$ alphas and $1.8 \mathrm{MeV}$ protons. Consequently, the $60 \mu \mathrm{m}$ film greatly reduces the number of tracks, as shown in Figure 2.

After etching, detectors 10-5 and 10-6 were examined microscopically. Figure 3a shows a photomicrograph of detector 10-5 obtained at 200× magnification showing the density of tracks obtained. The observed high density of tracks implies a high flux rate. However, these experiments typically last between one to two weeks and CR-39, like photographic film, is an integrating detector. When an event occurs, it is permanently stamped in the plastic of the detector. As a result, the signal does not get averaged away and the spatial distribution of the events can be determined, however, it is not known when the event(s) occurred. At 1000× magnification, top image in Figure 3b, it can be seen that there are dark, circular and elliptical tracks. There are also smaller, shallower tracks which are due to either latent tracks deeper inside the plastic, or to particles that barely impact the detector, or to highly energetic charged particles. When the microscope optics were focused on the bottom of the tracks, bottom image in Figure $3 \mathrm{~b}$, bright spots are observed inside the tracks. These bright spots indicate the endpoints of the particles that enter the detector and are caused by the curved bottom of the track acting like a lens when the detector is backlit [63]. The color, shape, and bright spot inside are features consistent with those observed for nuclear generated particle tracks.

To provide further experimental evidence that the observed tracks in Figures 2 and 3 were not due to chemical damage, a control experiment was done using a polyethylene coated CR-39 detector and electroplating using $\mathrm{CuCl}_{2}$ instead of $\mathrm{PdCl}_{2}$. For both $\mathrm{CuCl}_{2}$ and $\mathrm{PdCl}_{2}$, the same electrochemical reactions occur at the anode and cathode. Specifically, oxygen and chlorine gas evolution occurs at the cathode while deuterium gas evolution and metal electroplating occur at the cathode. In addition, the resultant $\mathrm{Cu}$ and $\mathrm{Pd}$ metallic deposits exhibit similar dendritic morphologies. The only significant difference is that $\mathrm{Pd}$ absorbs deuterium and $\mathrm{Cu}$ does not. No tracks were observed for the $\mathrm{CuCl}_{2}$ experiment. This experiment indicates that the tracks observed in the $\mathrm{PdCl}_{2}$ experiment cannot be attributed to a chemical species diffusing through the polyethylene film that attacks the surface of the detector. If this were the case, the CR-39 detector used in the $\mathrm{CuCl}_{2}$ experiment would have exhibited cloudiness and pitting, which it did 
not. The results also indicate that the $\mathrm{Cu}$ dendrites did not pierce through the polyethylene cover and into the detector. It can therefore be concluded that the observed pitting in the $\mathrm{PdCl}_{2}$ system is not due to either chemical or mechanical damage of the CR-39 detector.

\subsection{Results of the Automated Scanning}

Prior to microscopic examination and scanning, photographs of the CR-39 detector 10-5 were taken before and after etching. A photograph of the polyethylene-covered CR-39 detector 10-5 at the end of the experiment is shown in Figure 4a. Arrows indicate the placement of the Ag wires. The dark areas on the polyethylene cover are due to the Pd deposit. These dark areas indicate that the Pd deposit extended past the $\mathrm{Ag}$ wires and into the areas between the wires. Figure $4 \mathrm{~b}$ shows a photograph of the front surface of the detector 10-5 after etching. The white, cloudy areas are due to high track density. It can be seen that the density of tracks is highest near the vicinity of the Pd-coated Ag wires indicating that the cathode is the source of these tracks. Ohmic measurements using probes on both sides of the polyethylene film indicate that the deposit did not go through the $60 \mu \mathrm{m}$ thick polyethylene film. These measurements indicate that the Pd dendrites did not pierce through the polyethylene film and into the CR-39 detector.

After microscopic examination of the CR-39 detectors 10-5 and 10-6 was completed, the front and back surfaces of the detectors were scanned using an automated scanner. As discussed vide supra, the scanner uses a high quality microscope optical system operating at a magnification high enough to discriminate between tracks and background. Figure 5 illustrates how the automated system works. Figures $5 \mathrm{a}$ and $5 \mathrm{~b}$ are scanner images taken of the CR-39 detector 10-6 used in the SRI replication. To obtain the images shown in Figures 5a and 5b, the microscope optics were focused on the surface of the detector and the bottom of the pits, respectively. In Figure 5b, bright spots are observed inside the pits. The objects in the image were then identified by the system, Figure 5c. Fifteen measurements of each object in the image were then made by the system. These measurements include track diameter and length, optical density (average image contrast), and image symmetry. The system then uses image analysis algorithms to discriminate between etched tracks and background features. Based upon those measurements and the image analysis algorithms, some of the objects in the image were identified as nuclear particle generated tracks. These are designated by the light colored squares 
in Figure 5d. The objects designated by the dark colored squares did not meet the criteria used by the algorithm to positively identify them as nuclear particle generated tracks. These objects are either defects or scratches in the plastic, dust, or overlapping tracks (the algorithm ignores overlapping nuclear particle generated tracks).

The spatial distribution of positively identified tracks for the front and back surfaces of detector 10-5 are shown in Figures $4 \mathrm{c}$ and $4 \mathrm{~d}$, respectively. The automatic scanner ignores areas where there is a high density of overlapping tracks. This is illustrated in the mapping of the tracks shown in Figure 4c. In the photograph shown in Figure 4b, three cloudy areas are circled. Microscopic examination of these areas showed numerous overlapping tracks. The track density was too high for the scanner to accurately measure the contrast and size of the individual tracks. This is why no tracks have been identified by the scanner in these cloudy areas. On the backside of the detector, the identified tracks are not clearly associated with any of the wires. However, the density of tracks is greatest between the second and third wires. Looking at the photograph in Figure $4 \mathrm{a}$, it appears that the density of the Pd deposit is greater between wires 2 and 3 .

Figure 6 summarizes the scanned results obtained for a blank CR-39 detector. Both the front and back surfaces of the detector were scanned. For the blank detector, 147 tracks were observed on the front surface and 166 tracks on the back, for an average track density of 78 tracks cm ${ }^{-2}$. The size distributions of the front and back surfaces of the blank detector are shown in Figures $6 \mathrm{a}$ and $6 \mathrm{c}$, respectively. For both surfaces, there is a distribution of tracks between 1 and $5 \mu \mathrm{m}$ in diameter and a second distribution between 6 and $40 \mu \mathrm{m}$ in diameter. As discussed vide supra, the $60 \mu \mathrm{m}$ thick polyethylene film on the detector will block $7 \mathrm{MeV}$ alphas and $1.8 \mathrm{MeV}$ protons. The tracks in the $1-5 \mu \mathrm{m}$ range are likely due to very energetic protons with an estimated energy $\geq 10 \mathrm{MeV}$. Protons with this energy will be able to pass through the polyethylene film and would leave a small diameter track in the CR-39 detector. Oda et al. [64] did sequential etching of CR39 exposed to $10 \mathrm{MeV}$ protons. The track diameters were 1.0 and $2.6 \mu \mathrm{m}$ after removing 6.5 and $15 \mu \mathrm{m}$ of plastic, respectively. It is unlikely that the tracks in the $6-40 \mu \mathrm{m}$ size range are due to alpha particles given that the polyethylene film blocks alphas with energies $\leq 7 \mathrm{MeV}$. These tracks are most likely recoils resulting from cosmic ray spallation neutrons interactions with the constituents of the detector, i.e. proton, carbon, and oxygen atoms. Nakamura et al. [65] have 
observed thermal, 1-6 MeV, and $100 \mathrm{MeV}$ neutrons in the spectrum obtained for cosmic ray spallation neutrons. CR-39 detectors will not respond to thermal neutrons. Neutrons that are 1-6 $\mathrm{MeV}$ in energy will cause proton recoils that will produce tracks with sizes ranging between 5 and $30 \mu \mathrm{m}$ is diameter [34]. Neutrons with energies greater than $8 \mathrm{MeV}$ will cause proton, carbon, and oxygen recoils that will produce tracks in CR-39 with major axis $\geq 30 \mu \mathrm{m}$ [66]. Plots of minor vs. major axis of the tracks observed on the front and back surfaces are shown in Figures $6 \mathrm{~b}$ and $6 \mathrm{~d}$, respectively. The plots show that the majority of the tracks exhibit ellipticity indicating that the particles have entered the detector at angles less than $90^{\circ}$.

Figure 7 summarizes the scans of the front and back surfaces of the CR-39 detector 10-5 used in the SRI replication. The size distributions of tracks on the front and back surfaces of the detector are shown in Figures 7a and 7c, respectively. The number of tracks on the front and back surfaces are significantly greater than what is observed on the blank detector. On the front surface, 34,254 tracks were positively identified. Two size distributions are observed: 0 to 3.5 $\mu \mathrm{m}$ and 3.5 to $20 \mu \mathrm{m}$ in diameter. As can be seen in Figure 7a, the majority of the tracks ( 70\%) fall in the 0-3.5 $\mu \mathrm{m}$ size range. For the tracks in the 3.5-20 $\mu \mathrm{m}$ size range, the peak maximum occurs at $6.7 \mu \mathrm{m}$. A plot of minor vs. major axis of the tracks on the front surface is shown in Figure $7 \mathrm{~b}$. The line along the diagonal, where the minor and major axis are equal, represents particles that have entered the detector at a $90^{\circ}$ angle. The majority of the tracks fall in the circled area. In this region, the major axis is larger than the minor axis indicating that these particles entered the detector at oblique angles. On the back surface, 750 tracks were identified by the scanner. Approximately $40 \%$ of those tracks fall in the $0-3.5 \mu \mathrm{m}$ size distribution. The remainder of the tracks fall in the $3.5-40 \mu \mathrm{m}$ size range with the peak maximum occurring at $8.8 \mu \mathrm{m}$. Figure $7 \mathrm{~d}$ shows the plot of minor vs. major axis for the tracks identified on the back surface. The majority of the tracks fall in the circled region. Compared to the front surface, the tracks on the back surface exhibit greater ellipticity indicating that the angles of incidence are more acute.

Figure 8 summarizes the scans of the front and back surfaces of the CR-39 detector 10-6 used in the SRI replication. The results are similar to those observed for detector 10-5. Specifically there were significantly more tracks observed on the front surface than on the back surface. There are two populations of tracks on the front surface at 0-3.5 $\mu \mathrm{m}$ and 3.5-20 $\mu \mathrm{m}$ in diameter 
and that the majority of the tracks fall in the 0-3.5 $\mu \mathrm{m}$ size range. Likewise there are two populations of tracks on the back surface at 0-3.5 $\mu \mathrm{m}$ and 3.5-40 $\mu \mathrm{m}$ in diameter. Again the majority of the tracks fall in the at 0-3.5 $\mu \mathrm{m}$ size distribution. For both detectors, the average number of tracks that do not overlap (front and back) is 10406 tracks $\mathrm{cm}^{2}$. The actual number of tracks $\mathrm{cm}^{2}$ is greater than this as the scanner ignores regions where there is a high density of tracks. But an average track density of 10406 tracks $\mathrm{cm}^{2}$ is still greater than background by a factor of 133.4 .

From the scanned data, the flux of energetic particles can be estimated. The total number of positively identified particle tracks on the front surfaces of both detectors is 81667 . Approximately $60 \%$ of the detectors are covered with the Pd deposit, Figure 4a. The total area of deposit in contact with the front sides of both detectors is therefore $2.4 \mathrm{~cm}^{2}$. Because CR-39 is an example of a constantly integrating detector, it is not known when the energetic particles were produced. However, it is assumed that the emission of energetic particles occurred after the Pd had plated out at which time the current was ramped up. This encompassed a six day period. Consequently the average flux, in $2 \pi$, is estimated to be 0.42 particles $\mathrm{cm}^{-2} \mathrm{~s}^{-1}$. It should be noted that this average flux is the lower limit value as the scanner undercounts the number of tracks especially in high density areas where there is significant overlap between tracks.

\subsection{LET Analysis of CR-39 Detectors 10-5 and 10-6}

The scanned data obtained for detectors 10-5 and 10-6 were subjected to LET analysis to identify the charged particles that generated the tracks [59-61]. In this analysis, the scanned surfaces are "cathode" - the CR-39 surface closest to the cathode and "obverse" - side away from the cathode. The scanned area is $2.7 \times 10^{-3} \mathrm{~cm}^{2}$ and the LET bin width is $0.25 \mathrm{keV} / \mu \mathrm{m} \mathrm{CR}-39$. The work conducted in DIAS, NASA-JSC and NSSC has shown that background tracks are mainly due to radon alpha particles and are nearly the same. Therefore, since the background tracks are several orders of magnitude lower in number than the LENR-generated particle tracks, they can be ignored. From their LET characteristics, the LENR-generated particles detected with CR-39 detectors are mainly identified as protons and $\alpha$ particles. Neutrons produce proton recoils whose tracks have the same quality as proton and alpha particle generated nuclear tracks. 
Consequently, the LET analysis cannot differentiate between tracks caused by neutrons and alphas/protons.

Figures 9(a) and (b) show the LET spectra of differential fluence for the detected charged particles. In the figures, particles with LET $\leq 31.0 \mathrm{keV} / \mu \mathrm{m} \mathrm{CR}-39$ are protons and particles with LET $\geq 31.0 \mathrm{keV} / \mu \mathrm{m}$ CR-39 are $\alpha$ particles. The LET criterion, maximum LET value for protons, can be determined by the particles minimum range, i.e., the bulk etch value of CR-39 detectors. Figures 9(a) and (b) indicate that the LET values of protons and $\alpha$ particles measured with CR-39 detectors is from $\sim 3$ to $\sim 150 \mathrm{keV} / \mu \mathrm{m}$ CR-39; the LET spectrum for protons has several peaks, the major peak is at $~ 3.25-3.50 \mathrm{keV} / \mu \mathrm{m} \mathrm{CR}-39$.

The number of charged particles observed are summarized in Table 1. Results in the table indicate that: (a) for the cathode surface of CR-39 detectors, events $(\mathrm{A}=1,2)$ are $\sim 96.3 \%$ of total events and events $(\mathrm{A} \geq 3$ ) are $\sim 3.7 \%$ of total; (b) for the obverse surface of CR-39 detectors, events $(\mathrm{A}=1,2)$ are $\sim 86.4 \%$ of total and particles $(\mathrm{A} \geq 3)$ are $13.6 \%$ of total. Particles that are $\mathrm{A} \geq 3$ are target fragments of CR-39 nuclei.

In the SRI immersion experiments, a $60 \mu \mathrm{m}$ thick polyethylene film separated the detector from the cathode. The $\sim 60 \mu \mathrm{m}$ polyethylene film between the cathode of the $\mathrm{Pd} / \mathrm{D}$ system and the surface of CR-39 detector causes charged particles to lose $~ 2 \mathrm{MeV} /$ nucleon. Therefore, a proton requires an energy $>1.8 \mathrm{MeV}$ to transit the film and an alpha will need $>7 \mathrm{MeV}$. This fact tells us that $\alpha$ particles observed in CR-39 detectors are secondary particles produced by very fast primary protons and neutrons. Therefore the total energy for protons observed should be the energy observed plus the minimum energy and the total energy for $\alpha$ particles is the same as those observed.

For the data observed on CR-39 obverse surfaces (side opposite the cathode), the energy absorption in CR-39 should be considered. The minimum energy to pass through the $\sim 1 \mathrm{~mm}$ thickness of CR-39 is $\sim 10 \mathrm{MeV}$ for protons and $\sim 40 \mathrm{MeV}$ for $\alpha$ particles. Protons with energies greater than $10 \mathrm{MeV}$ can reach the obverse surface, but they need to be nearly perpendicular to the surface. The particles identified as alphas by the LET analysis are likely due to secondary 
recoil particles whose tracks are similar to those created by 2-15 MeV alpha particles. Therefore the majority of tracks observed on the obverse surfaces must be due to secondary particles, i.e., recoils. The energies reported in Figure 10(b) are measured energies, i.e., without the minimum energy correction. Figures 10(a) and (b) show the energy distribution of particles produced by the $\mathrm{Pd} / \mathrm{D}$ system and measured with CR-39 detectors. The major proton peak is at $\sim 11.5-12$ $\mathrm{MeV}$ for the cathode CR-39 surfaces and $\sim 9.75 \mathrm{MeV}$ for the obverse CR-39 surfaces. The distribution of $\alpha$ particles is nearly uniform because they consist of either secondary particles or neutron recoils.

From the LET analysis, the number of protons and alphas of a given energy is known. This information is summarized in Figure 10. Using these data, the total energy released by the LENR-generated particles can be estimated. For detectors 10-5 and 10-6 used in the SRI LENR experiments, the calculated energies for the measured protons and $\alpha$ particles are summarized in Table 2. The particles emitted by the cathode will travel in all directions. These particles will be produced throughout the thickness of the Pd deposit. Not all of these particles will reach the CR39 detector. Consequently, the particle tracks that were scanned and analyzed are only some of the total particles generated in the LENR processes occurring inside the Pd lattice. In addition, some of the detected charged particles are produced through the interactions between neutrons and CR-39 material. Since the detection efficiency of CR-39 detectors for neutrons with energies from $\sim 1 \mathrm{MeV}$ to $20 \mathrm{MeV}$ is $\sim 10^{-4}$ to $10^{-3}[49,67,68]$, the actual number of particles that entered the CR-39 detector should be higher than the number showed in Figure 10. Taking into account the poor neutron efficiency of CR-39 and the fact that not all particles, charged and neutral, will reach the detector, the actual total energy released by all the LENR-generated particles with high LET should be higher than that contributed by the observed particles.

\subsection{CONCLUSIONS}

In this communication, the results of microscopic examination, scanning, and LET analysis of CR-39 detectors used in $\mathrm{Pd} / \mathrm{D}$ co-deposition experiments were discussed. In these experiments, a $60 \mu \mathrm{m}$ thick polyethylene film separated the detector from the cathode. This film protected the detector from mechanical and chemical damage. It was shown that tracks, significantly above background, were observed on the front and back surfaces of the detector. 
The tracks were dark, either circular or elliptical in shape, and exhibited bright centers when focusing deeper in the plastic. These properties are consistent with those observed for nuclear generated tracks. On the front surface of the detectors, the tracks correlated with the placement

of the Ag wires. Based upon microscopic examination of the tracks; the size distributions and plots of major vs minor axis obtained from the scanner; and LET analysis, taking into account the $60 \mu \mathrm{m}$ thick polyethylene film between the cathodes and the detector, the tracks on the front surface were tentatively identified as due to $\geq 1.8 \mathrm{MeV}$ protons, $\geq 7 \mathrm{MeV}$ alphas, and secondary particles due to recoils from either energetic protons and/or neutrons. On the back surface of the detectors, the tracks are tentatively identified as $\geq 11.8 \mathrm{MeV}$ protons and/or recoils from either energetic protons and/or neutrons.

The detector designated 10-5 was then subjected to additional examination using sequential etching to further elucidate the identity of the particles that generated the tracks in the CR-39 detector. The results of this analysis is discussed in part 2 of these communiqués. As will be seen, both analyses (LET spectrum and sequential etching) gave complementary results. The analyzed data support Fleischmann's conjecture that nuclear processes occur in the Fleischmann and Pons (F\&P) experiment, and indirectly support the notion that excess heat in the F\&P experiment is of a nuclear origin.

\subsection{ACKNOWLEDGEMENTS}

The authors dedicate this communication to the memory of Dr. Andrei Lipson of the Russian Academy of Sciences who passed away in November 2009. He was involved in the sequential etching analysis of the detectors used in the SRI experiment.

This effort was funded by the Defense Threat Reduction Agency (DTRA), and JWK Corporation. The authors would like to thank Dr. Gary Phillips, nuclear physicist, retired from the Naval Research Laboratory, US Navy, Radiation Effects Branch for valuable discussions in interpreting the optical data. The authors thank Steve Krivit of New Energy Times for initiating the SRI replication of the Pd/D co-deposition CR-39 results. We also thank Dr. Fran Tanzella, of SRI, for conducting the experiments irradiating CR-39 under the Pd/D co-deposition protocol 
described in US Patent 8,419,919. We wish to thank NASA-JSC-SRAG and USRA (Universities Space Research Association) for the use of research facilities for LENR data analysis.

\section{REFERENCES}

[1] Holmlid L., Olafsson S.Spontaneous ejection of high-energy particles from ultra-dense deuterium D(0). Int. J. of Hydrogen Energy 2015; 40: 10559-67.

[2] Lin G.H., Kainthla R.C., Packham N.J.C., Velev O., Bockris J.O’M. On electrochemical tritium production. Int. J. of Hydrogen Energy 1990; 15: 537-50.

[3] Kozima H., Arai K., Yoshimoto K. Tritium and ${ }^{4} \mathrm{He}$ data by Chien et al. confirmed the cold fusion phenomenon. Int. J. of Hydrogen Energy 2000; 25: 509-11.

[4] Packham N.J.C., Wolf K.L., Wass J.C., Kainthla R.C., Bockris J.O. Production of tritium from deuterium oxide (D2O) electrolysis at a palladium cathode. J. Electroanal. Chem.

Interfacial Electrochem. 1989; 270: 451-8.

[5] Golubnichii P.I., Koval'chuk E.P., Merzon G.I., Filonenko A.O., Tsarev V.A., Tsarik A.A. Recording of neutrons and tritium from massive palladium targets during electrolytic saturation with deuterium. Pis'ma Zh. Tekh. Fiz. 1990; 16: 46-50.

[6] Matsumoto O., Kimura K., Saito Y., Uyama H., Yaita T. Detection of tritium in cathode materials after the electrolysis of $\mathrm{D}_{2} \mathrm{SO}_{4}-\mathrm{D}_{2} \mathrm{O}$ solution. Denki Kagaku oyobi Kogyo Butsuri Kagaku 1990; 58: 471-4.

[7] Storms E., Talcott C. Electrolytic tritium production. Fusion Technol. 1990; 17: 680-95.

[8] Venkateswaran G., Moorthy P.N., Venkateswarlu K.S., Guha S.N., Yuvaraju B., Datta, T., et al. Burst neutron emission and tritium generation from a palladium cathode electrolytically loaded with deuterium. Fusion Technol. 1990; 18: 60-6.

[9] Wolf K.L., Packham N.J.C., Lawson D., Shoemaker J., Cheng F., Wass J.C., Neutron emission and the tritium content associated with deuterium-loaded palladium and titanium metals. J. Fusion Energy 1990; 9: 105-13.

[10] Mengoli G., Fabrizio M., Manduchi C., Zannoni G., Riccardi L., Veronesi F., et al. The observation of tritium in the electrolysis of heavy water at palladium sheet cathodes. J.

Electroanal. Chem. Interfacial Electrochem. 1991; 304: 279-87.

[11] Chien C.C., Hodko D., Minevski Z., Bockris J.O.M. On an electrode producing massive quantities of tritium and helium. J. Electroanal. Chem. 1992; 338: 189-212.

[12] Chien C.C., Huang T.C. Tritium production by electrolysis of heavy water. Fusion Technol. 1992; 22: 391-4. 
[13] Gozzi D., Cignini P.L., Tomellini M., Frullani S., Garibaldi F., Ghio, F., et al. Neutron and tritium evidence in the electrolytic reduction of deuterium on palladium electrodes. Fusion Technol. 1992; 21: 60-74.

[14] Mengoli G., Fabrizio M., Manduchi C., Zannoni G., Riccardi L., Buffa A. Tritium and neutron emission in heavy water electrolysis at palladium and titanium cathodes. J. Electroanal. Chem. Interfacial Electrochem. 1992; 322: 107-17.

[15] Stukan R.A., Rumyantsev Y.M., Shishkov A.V. Generation of hard radiation and production of tritium in the electrolysis of heavy water. Khim. Vys. Energ. 1993; 27: 65-70.

[16] Takahashi A. Production of neutron, tritium, and excess heat. Oyo Butsuri 1993; 62: 707-9.

[17] Will F.G., Cedzynska K., Linton D.C. Reproducible tritium generation in electrochemical cells employing palladium cathodes with high deuterium loading. J. Electroanal. Chem. 1993; 360: 161-76.

[18] Mizuno T., Akimoto T., Sato N. Neutron evolution from annealed palladium cathode in lithium hydroxide-d - deuterium oxide solution. Denki Kagaku oyobi Kogyo Butsuri Kagaku 1989; 57: 742-3.

[19] Perfetti P., Cilloco F., Felici R., Capozi M., Ippoliti A. Neutron emission under particular nonequilibrium conditions from palladium and titanium electrolytically charged with deuterium. Nuovo Cimento Soc. Ital. Fis., D 1989; 11D: 921-6.

[20] Sinha B., Viyogi Y.P., Chattopadhyaya S., Dutta Mazumdar M.R., Murthy G.S.N., Muthukrishnan G., et al. Observation of neutron bursts in electrolysis of heavy water. Indian J. Technol. 1989; 27: 275-7.

[21] Chen X., Crooks R.M., Fiore C., Gaudreau M.P.J., Hwang I., Li C.K., et al. Measurement and analysis of neutron and gamma-ray emission rates, other fusion products, and power in electrochemical cells having palladium cathodes. J. Fusion Energy 1990; 9: 133-48.

[22] Matsumoto O., Kimura K., Saito Y., Uyama H., Yaita T. Detection of neutrons in electrolysis of heavy water (D2SO4-D2O) solution by means of fission track method. Denki Kagaku oyobi Kogyo Butsuri Kagaku 1990; 58: 147-50.

[23] Takahashi A., Takeuchi T., Iida T., Watanabe M. Emission of $2.45 \mathrm{MeV}$ and higher energy neutrons from heavy water-palladium cell under biased-pulse electrolysis. J. Nucl. Sci. Technol. 1990; 27: 663-6.

[24] Bittner M., Ludwig G., Meister A., Mueller J., Ohms D., Paffrath E., et al. Evidence for the production of $\mathrm{d}$-d fusion neutrons during electrolytic infusion of deuterons into a palladium cylinder. Fusion Technol. 1991; 19: 2119-24. 
[25] Sato T., Okamoto M., Kim P., Fujii Y., Aizawa O. Detection of neutrons in electrolysis of heavy water. Fusion Technol. 1991; 19: 357-63.

[26] Takagi R., Numata H., Ohno I., Kawamura K., Haruyama S. Neutron emission during a long-term electrolysis of heavy water. Fusion Technol. 1991; 19: 2135-9.

[27] Soifer V.N., Goryachev V.A., Salyuk A.N., Sergeev A.F. Neutron emission during heavy water electrolysis. Appl. Radiat. Isot. 1992; 43: 1041-4.

[28] Blagus S., Bogovac M., Drasner A., Vukovic M. Evidence for neutron production during heavy water electrolysis on palladium electrode. Fusion Technol. 1994; 26: 105-9.

[29] Matsumoto T. Observation of new particles emitted during cold fusion. Fusion Technol. 1990; 18: 356-60.

[30] Taniguchi R., Yamamoto T., Irie S. Detection of charged particles emitted by electrolytically induced cold nuclear fusion. Japanese Journal of Applied Physics, Part 2 Letters 1989; 28: L2021-L2023.

[31] Taniguchi R., Yamamoto T., Irie S. Fine structure of the charged particle bursts induced by water- $\mathrm{d}_{2}$ electrolysis. Bull. Univ. Osaka Prefect., Ser. A 1990; 39: 233-44.

[32] Morrey J.R., Caffee M.W., Farrar H.I.V., Hoffman N.J., Hudson G.B., Jones R.H., et al. Measurements of helium in electrolyzed palladium. Fusion Technol. 1990; 18: 659-68.

[33] Miles M.H., Ostrom G.S. Helium production during the electrolysis of heavy water in cold fusion experiments. J. Electroanal. Chem. Interfacial Electrochem. 1991; 304: 271-8.

[34] Liaw B.Y., Tao P.L., Liebert B.E. Helium analysis of palladium electrodes after molten salt electrolysis. Laser Chem. 1992; 12: 92-7.

[35] Miles M.H., Hollins R.A., Bush B.F., Lagowski J.J., Miles R.E. Correlation of excess power and helium production during $\mathrm{D}_{2} \mathrm{O}$ and $\mathrm{H}_{2} \mathrm{O}$ electrolysis using palladium cathode. J. Electroanal. Chem. 1993; 346: 99-117.

[36] Miles M.H., Bush B.F., Lagowski J.J. Anomalous effects involving excess power, radiation, and helium production during $\mathrm{D}_{2} \mathrm{O}$ electrolysis using palladium cathodes. Fusion Technol. 1994; 25: 478-86.

[37] Mosier-Boss P.A. A review on nuclear products generated during low-energy nuclear reactions (LENR). J. Condensed Matter Nucl. Sci. 2012; 6: 135-48.

[38] Czerski K., Hike A., Biller A., Heide P., Ruprecht G. Enhancement of the electron screening effect for $\mathrm{d}+\mathrm{d}$ fusion reactions in metallic environments. Europhys. Lett. 2001; 54: 119-55. 
[39] Kasagi J., Yuki H., Baba T., Noda T. Ohtsuki T., Lipson A.G. Strongly enhanced DD fusion reactions in metals observed for keV D ${ }^{+}$bombardment. J. Phys. Soc. Jpn. 2002; 71: 2881-85.

[40] Greife U., Gorris F., Junker M., Rolfs C., Zahnow D. Opperheimer-Phillips effect and electron screening in $d+d$ fusion reactions. Z. Phys. A. 1995; 351: 107-112.

[41] Szpak S., Mosier-Boss P.A., Gordon F.E. Further evidence of nuclear reactions in the Pd/D lattice: emission of charged particles. Naturwissenschaften 2007; 94: 511-514.

[42] Séguin F.H., Frenje J.A., Li C.K., Hicks D.G., Kurebayashi S., Schwartz B.-E., et al. Spectrometry of charged particles from inertial-confinement-fusion plasmas. Rev. Sci. Instru. 2003; 74: 975-95.

[43] Mosier-Boss P.A., Szpak S., Gordon F.E., Forsley L.P.G. Use of CR-39 in Pd/D codeposition experiments. Eur. Phys. J. Appl. Phys. 2007; 40: 293- 304.

[44] Mosier-Boss P.A., Szpak S., Gordon F.E., Forsley L.P.G. Characterization of tracks in CR39 detectors obtained as a result of Pd/D co-deposition. Eur. Phys. J. Appl. Phys. 2009; 46: $30901 \mathrm{p} 1-12$.

[45] Robertson N., Saito H., Yurkovic J., Zakskorn S. Field assisted electroplating. J. Sci. Explor. 2009; 23: 452-5.

[46] Mosier-Boss P.A., Dea J.Y., Gordon, F.E., Forsley, L.P.G., Miles, M.H. Review of twenty years of LENR research using Pd/D co-deposition. J. Condensed Matter Nucl. Sci. 2011; 4: 17387.

[47] Letts D., Hagelstein P.L. Modified Szpak protocol for excess heat. J. Condensed Matter Nucl. Sci. 2012; 6: 44-54.

[48] Henke R. H., Ogura K., Benton E.V. Standard methods for measurement of bulk etch in CR-39. Int. J. Rad. Appl. And Instrumentation. Part D. Nucl. Tracks and Rad. Meas. 1986; 12: 307-10.

[49] Somogyi G. Processing of plastic track detectors. Nucl. Track Detect. 1977; 1: 3-18.

[50] Zhou D., Semones E., Weyland M., Benton E.R. LET calibration for CR-39 detectors in different oxygen environments. Radiat. Meas. 2007; 42: 1499-506.

[51] Benton E.V. Heavy particle range-energy relations for dielectric nuclear track detectors. Nucl. Instr. Meth.1969; 67: 87-92.

[52] Weaver B.A., Westphal A.J. Energy loss of relativistic heavy ions in matter. Nucl. Instr. Meth. Phys. Res. Section B 2002; 187: 285-301. 
[53] O’Sullivan D., Zhou D., Heinrich W., Roesler S., Donnelly J., Keegan R. et al.Cosmic rays and dosimetry at aviation altitudes. Radiat. Meas. 1999; 31: 579-84.

[54] O'Sullivan D., Zhou D., Semones E., Heinrich W., Flood E. Dose equivalent, absorbed dose and charge spectrum investigation in low Earth orbit. Adv. Space Res. 2004; 34: 1420-3.

[55] Zhou D., Semones E., Gaza R., Johnson S., Zapp N., Weyland M. Radiation measured for ISS-Expedition 12 with different dosimeters. Nucl. Instr. Meth. Phys. Res. Section A 2007; 580: 1283-9.

[56] Zhou D., Semones E., Gaza R., Johnson S., Zapp N., Weyland M., et al. Radiation measured with different dosimeters during STS-121 space mission. Acta Astron. 2009; 64: 43747.

[57] Zhou D., Semones E., Gaza R., Johnson S., Zapp N., Lee K., et al. Radiation measured during ISS-Expedition 13 with different dosimeters. Adv. Space Res. 2009; 43: 1212-9.

[58] Zhou D., Semones E., O'Sullivan D., Zapp N., Weyland M., Reitz G., et al. Radiation measured for MATROSHKA-1 experiment with passive dosimeters. Acta Astron. 2010; 66: $301-8$.

[59] Zhou D. Chapter 1: Methods using CR-39 plastic nuclear track detectors in radiation research, In: Sidorov M., Ivanov O., editors. Nuclear track detectors - design, methods and applications, New York: Nova Science Publishers Inc., 2010, p. 1-106.

[60] Zhou D.. CR-39 plastic nuclear track detectors in physics research. New York: Nova Science Publishers Inc.; 2012.

[61] Zhou D.Z., Wang C., Sun Y.Q., Liang J.B., Zhu G.W., Forsley, L.P.G., , et al., Energetic particles generated in earlier Pd+ D nuclear reactions. J. Condensed Matter Nucl. Sci. 2015; 15: $33-43$.

[62] Ziegler J.F., Biersack J.P. The stopping and range of ions in solids. New York: Pergamon, 1985.

[63] Nikezic D., Yu K.N. Formation and growth of tracks in nuclear track materials. Mat. Sci. Eng. R. 2004; 46: 51-123.

[64] Oda K., Ito M., Miyake H., Michijima M. Track formation in CR-39 detectors exposed to D-T neutrons. Nucl. Instr. and Meth. in Phy. Res. Section B 1988; 35: 50-6.

[65]. Nakamura T, Nunomiya T., Abe S., Terunuma K., Suzuki H. Sequential measurements of cosmic-ray neutron spectrum and dose rate at sea level in Sendai, Japan. J. Nucl. Sci. Technol. $2005 ; 42: 843-53$. 
[66] Phillips G.W., Spann J.E., Bogard J.S., VoDinh T., Emfietzoglou D., Devine R.T., et al. Neutron spectrometry using CR-39 track etch detectors. Radiat. Protect. Dosim. 2006; 120: 45760 .

[67] Benton E.V., Frank A. L., Oswald R.A., Wheeler, R.V. Proton recording neutron dosimeter for personnel monitoring. Nucl. Tracks, Suppl. 1980; 2: 469-72.

[68] Griffith R. V., Tommasino L. Etch track detectors in radiation dosimetry; In: Kase K.R., Bjärngard B.E., Attix F.H. editors. Dosimetry of ionizing radiation, vol. III, Berkeley: 1991, p 323-426. 


\section{TABLES}

Table 1: Events observed for different experiments and detector surfaces.

\begin{tabular}{|c|c|c|c|c|c|c|c|c|c|}
\hline Detector & Surface & \multicolumn{4}{|c|}{ Number of Events, $\mathrm{N}^{\mathrm{a}}$} & \multicolumn{4}{c|}{ Ratio (\%) } \\
\hline & & $\mathrm{N}_{1}(\mathrm{~A}=1)$ & $\mathrm{N}_{2}(\mathrm{~A}=2)$ & $\mathrm{N}_{3}(\mathrm{~A} \geq 3)$ & $\mathrm{N}(\mathrm{Total})$ & $\mathrm{N}_{1} / \mathrm{N}$ & $\mathrm{N}_{2} / \mathrm{N}$ & $\mathrm{N}_{3} / \mathrm{N}$ & $\left(\mathrm{N}_{1}+\mathrm{N}_{2}\right) / \mathrm{N}$ \\
\hline $10-5$ & Cathode & 26516 & 6307 & 1431 & 34254 & 77.4 & 18.4 & 4.2 & 95.8 \\
\hline & Obverse & 448 & 198 & 104 & 750 & 59.7 & 26.4 & 13.9 & 86.1 \\
\hline $10-6$ & Cathode & 33815 & 12241 & 1357 & 47413 & 71.3 & 25.8 & 2.9 & 97.1 \\
\hline & Obverse & 511 & 210 & 111 & 832 & 61.5 & 25.2 & 13.3 & 86.7 \\
\hline
\end{tabular}

a. A is the mass of the particle.

Table 2: Energies carried by the observed particles with high LET.

\begin{tabular}{|c|c|c|c|c|c|c|}
\hline Detector & Surface & \multicolumn{2}{|c|}{ Total Particle Energy, MeV } & \multicolumn{2}{c|}{ Ratio (\%) } \\
\hline & & $\mathrm{E}_{1}(\mathrm{~A}=1)^{\mathrm{a}}$ & $\mathrm{E}_{2}(\mathrm{~A}=2)^{\mathrm{b}}$ & $\mathrm{E}=\mathrm{E}_{1}+\mathrm{E}_{2}$ & $\mathrm{E}_{1} / \mathrm{E}$ & $\mathrm{E}_{2} / \mathrm{E}$ \\
& & & & & & \\
\hline $10-5$ & Cathode & 266279 & 50548 & 316827 & 84 & 16 \\
\hline & Obverse & 3596 & 1388 & 4984 & 72 & 28 \\
\hline $10-6$ & Cathode & 327263 & 103823 & 431086 & 76 & 24 \\
\hline & Obverse & 4090 & 1283 & 5373 & 76 & 24 \\
\hline
\end{tabular}

a. $E_{1}=\Sigma N_{i} E_{i}$ where $N_{i}$ is the number of protons with energy $E_{i}$

b. $E_{2}=\Sigma N_{j} E_{j}$ where $N_{j}$ is the number of alphas with energy $E_{j}$ 


\section{FIGURE CAPTIONS}

Figure 1. (a) Schematic of the rectangular, butyrate electrochemical cell showing the orientation of the cell components and the magnets. (b) Schematic of the $0.25 \mathrm{~mm}$ diameter $\mathrm{Ag}$ wire cathode. The continuous, single-wire cathode runs vertically over the CR-39 detector (solid lines) and under the plastic support (dashed lines) through holes in the plastic support at the top and bottom. $\mathrm{PE}=$ polyethylene.

Figure 2. Photomicrographs obtained at 200x magnification for CR-39 detectors used in Pd/D co-deposition experiments (a) without and (b) with $60 \mu \mathrm{m}$ polyethylene covers between the cathode and the detector. The time duration of both experiments was the same.

Figure 3. (a) Photomicrograph of the CR-39 detector 10-5 used in the SRI replication obtained at a magnification of $200 \times$. (b) Photomicrograph obtained at $1000 \times$ for the area indicated in (a). The top image was taken with the microscope optics focused on the surface of the detector. The bottom image is an overlay of two images taken at different focusing depths (surface of the detector and the bottom of the tracks).

Figure 4. (a) Photograph (provided by F. Tanzella of SRI) of the surface of the detector 10-5 facing the cathode obtained at the end of the experiment. The polyethylene cover is on the surface of the detector. Arrows indicate the placement of the Ag wires, which are numbered. (b) Photograph (provided by F. Tanzella of SRI) of the detector 10-5 after it was etched. The five dots on the upper right hand corner were created by pushing a pin into the detector. These marks indicate which side of the detector was facing the cathode. Circled areas indicate a high density of tracks. Scanned results of the detector that shows the spatial distribution of tracks on the (c) front and (d) back surfaces of the detector.

Figure 5. Photomicrographs of the CR-39 detector 10-6 used in the SRI replication obtained using the automated scanning track analysis system operating at $200 \times$. The field of view is 500 $\mu \mathrm{m}$ by $600 \mu \mathrm{m}$. (a) Image obtained with the optics focused on the surface of the detector. (b) Image obtained with the optics focused on the bottom of the pits. Images (c) and (d) summarize the results of the track analysis performed by the automated scanner. (c) The scanner has 
identified objects in the image. These are indicated by the small square numbers. (d) Based upon further analysis, the automated scanner has identified true tracks (light squares) from non-tracks (dark squares).

Figure 6. Scanned results obtained for a blank CR-39 detector. Front surface (147 tracks): (a) size distribution and (b) plot of minor axis and major axis. Back surface (166 tracks): (c) size distribution and (d) plot of minor axis and major axis.

Figure 7. Scanned results obtained for the CR-39 detector 10-5 used in the SRI replication. Front surface (34,254 tracks, spatial distribution of tracks shown in Figure 4c): (a) size distribution and (b) plot of minor axis and major axis. Back surface (750 tracks, spatial distribution of tracks shown in Figure 4d): (c) size distribution and (d) plot of minor axis and major axis. In (b) and (d), the circled areas indicate the bulk of the tracks.

Figure 8. Scanned results obtained for the CR-39 detector 10-6 used in the SRI replication. Front surface (47,413 tracks): (a) size distribution and (b) plot of minor axis and major axis. Back surface (832 tracks): (c) size distribution and (d) plot of minor axis and major axis.

Figure 9. LET spectra of differential fluence of (a) cathode surface of CR-39 detectors and (b) obverse surface of CR-39 detector.

Figure 10. Energy distribution of particles for (a) cathode surface of CR-39 detectors and (b) obverse surface of CR-39 detectors. 


\section{TABLES}

Table 1: Events observed for different experiments and detector surfaces.

\begin{tabular}{|c|l|c|c|c|c|c|c|c|c|c|}
\hline Detector & Surface & \multicolumn{4}{|c|}{ Number of Events, $\mathrm{N}^{\mathrm{a}}$} & \multicolumn{4}{c|}{ Ratio (\%) } \\
\hline & & $\mathrm{N}_{1}(\mathrm{~A}=1)$ & $\mathrm{N}_{2}(\mathrm{~A}=2)$ & $\mathrm{N}_{3}(\mathrm{~A} \geq 3)$ & $\mathrm{N}(\mathrm{Total})$ & $\mathrm{N}_{1} / \mathrm{N}$ & $\mathrm{N}_{2} / \mathrm{N}$ & $\mathrm{N}_{3} / \mathrm{N}$ & $\left(\mathrm{N}_{1}+\mathrm{N}_{2}\right) / \mathrm{N}$ \\
\hline $10-5$ & Cathode & 26516 & 6307 & 1431 & 34254 & 77.4 & 18.4 & 4.2 & 95.8 \\
\hline & Obverse & 448 & 198 & 104 & 750 & 59.7 & 26.4 & 13.9 & 86.1 \\
\hline $10-6$ & Cathode & 33815 & 12241 & 1357 & 47413 & 71.3 & 25.8 & 2.9 & 97.1 \\
\hline & Obverse & 511 & 210 & 111 & 832 & 61.5 & 25.2 & 13.3 & 86.7 \\
\hline
\end{tabular}

a. A is the mass of the particle.

Table 2: Energies carried by the observed particles with high LET.

\begin{tabular}{|c|c|c|c|c|c|c|}
\hline Detector & Surface & \multicolumn{2}{|c|}{ Total Particle Energy, MeV } & \multicolumn{2}{c|}{ Ratio (\%) } \\
\hline & & $\mathrm{E}_{1}(\mathrm{~A}=1)^{\mathrm{a}}$ & $\mathrm{E}_{2}(\mathrm{~A}=2)^{\mathrm{b}}$ & $\mathrm{E}=\mathrm{E}_{1}+\mathrm{E}_{2}$ & $\mathrm{E}_{1} / \mathrm{E}$ & $\mathrm{E}_{2} / \mathrm{E}$ \\
& & & & & & \\
\hline $10-5$ & Cathode & 266279 & 50548 & 316827 & 84 & 16 \\
\hline & Obverse & 3596 & 1388 & 4984 & 72 & 28 \\
\hline $10-6$ & Cathode & 327263 & 103823 & 431086 & 76 & 24 \\
\hline & Obverse & 4090 & 1283 & 5373 & 76 & 24 \\
\hline
\end{tabular}

a. $\mathrm{E}_{1}=\Sigma \mathrm{N}_{\mathrm{i}} \mathrm{E}_{\mathrm{i}}$ where $\mathrm{N}_{\mathrm{i}}$ is the number of protons with energy $\mathrm{E}_{\mathrm{i}}$

b. $E_{2}=\Sigma N_{j} E_{j}$ where $N_{j}$ is the number of alphas with energy $E_{j}$ 


\section{FIGURE CAPTIONS}

Figure 1. (a) Schematic of the rectangular, butyrate electrochemical cell showing the orientation

of the cell components and the magnets. (b) Schematic of the $0.25 \mathrm{~mm}$ diameter Ag wire cathode. The continuous, single-wire cathode runs vertically over the CR-39 detector (solid lines) and under the plastic support (dashed lines) through holes in the plastic support at the top and bottom. $\mathrm{PE}=$ polyethylene.

Figure 2. Photomicrographs obtained at 200x magnification for CR-39 detectors used in Pd/D co-deposition experiments (a) without and (b) with $60 \mu \mathrm{m}$ polyethylene covers between the cathode and the detector. The time duration of both experiments was the same.

Figure 3. (a) Photomicrograph of the CR-39 detector 10-5 used in the SRI replication obtained at a magnification of $200 \times$. (b) Photomicrograph obtained at $1000 \times$ for the area indicated in (a). The top image was taken with the microscope optics focused on the surface of the detector. The bottom image is an overlay of two images taken at different focusing depths (surface of the detector and the bottom of the tracks).

Figure 4. (a) Photograph (provided by F. Tanzella of SRI) of the surface of the detector 10-5 facing the cathode obtained at the end of the experiment. The polyethylene cover is on the surface of the detector. Arrows indicate the placement of the Ag wires, which are numbered. (b) Photograph (provided by F. Tanzella of SRI) of the detector 10-5 after it was etched. The five dots on the upper right hand corner were created by pushing a pin into the detector. These marks indicate which side of the detector was facing the cathode. Circled areas indicate a high density of tracks. Scanned results of the detector that shows the spatial distribution of tracks on the (c) front and (d) back surfaces of the detector.

Figure 5. Photomicrographs of the CR-39 detector 10-6 used in the SRI replication obtained using the automated scanning track analysis system operating at $200 \times$. The field of view is 500 $\mu \mathrm{m}$ by $600 \mu \mathrm{m}$. (a) Image obtained with the optics focused on the surface of the detector. (b) Image obtained with the optics focused on the bottom of the pits. Images (c) and (d) summarize the results of the track analysis performed by the automated scanner. (c) The scanner has 
identified objects in the image. These are indicated by the small square numbers. (d) Based upon further analysis, the automated scanner has identified true tracks (light squares) from non-tracks (dark squares).

Figure 6. Scanned results obtained for a blank CR-39 detector. Front surface (147 tracks): (a) size distribution and (b) plot of minor axis and major axis. Back surface (166 tracks): (c) size distribution and (d) plot of minor axis and major axis.

Figure 7. Scanned results obtained for the CR-39 detector 10-5 used in the SRI replication. Front surface (34,254 tracks, spatial distribution of tracks shown in Figure 4c): (a) size distribution and (b) plot of minor axis and major axis. Back surface (750 tracks, spatial distribution of tracks shown in Figure 4d): (c) size distribution and (d) plot of minor axis and major axis. In (b) and (d), the circled areas indicate the bulk of the tracks.

Figure 8. Scanned results obtained for the CR-39 detector 10-6 used in the SRI replication. Front surface (47,413 tracks): (a) size distribution and (b) plot of minor axis and major axis. Back surface (832 tracks): (c) size distribution and (d) plot of minor axis and major axis.

Figure 9. LET spectra of differential fluence of (a) cathode surface of CR-39 detectors and (b) obverse surface of CR-39 detector.

Figure 10. Energy distribution of particles for (a) cathode surface of CR-39 detectors and (b) obverse surface of CR-39 detectors. 
Figure 1
(+)
(-)

(a)
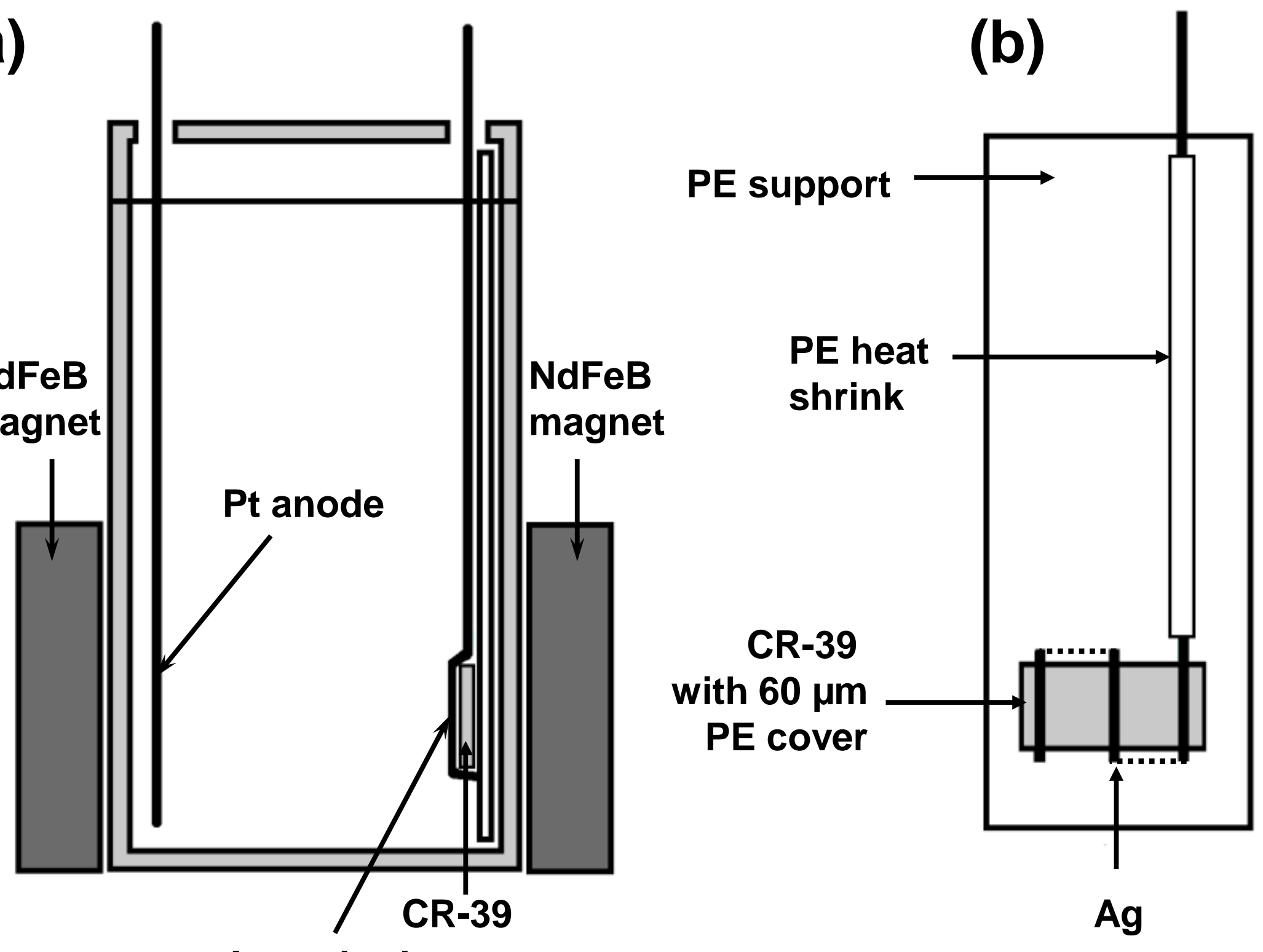

Ag cathode 
(a)

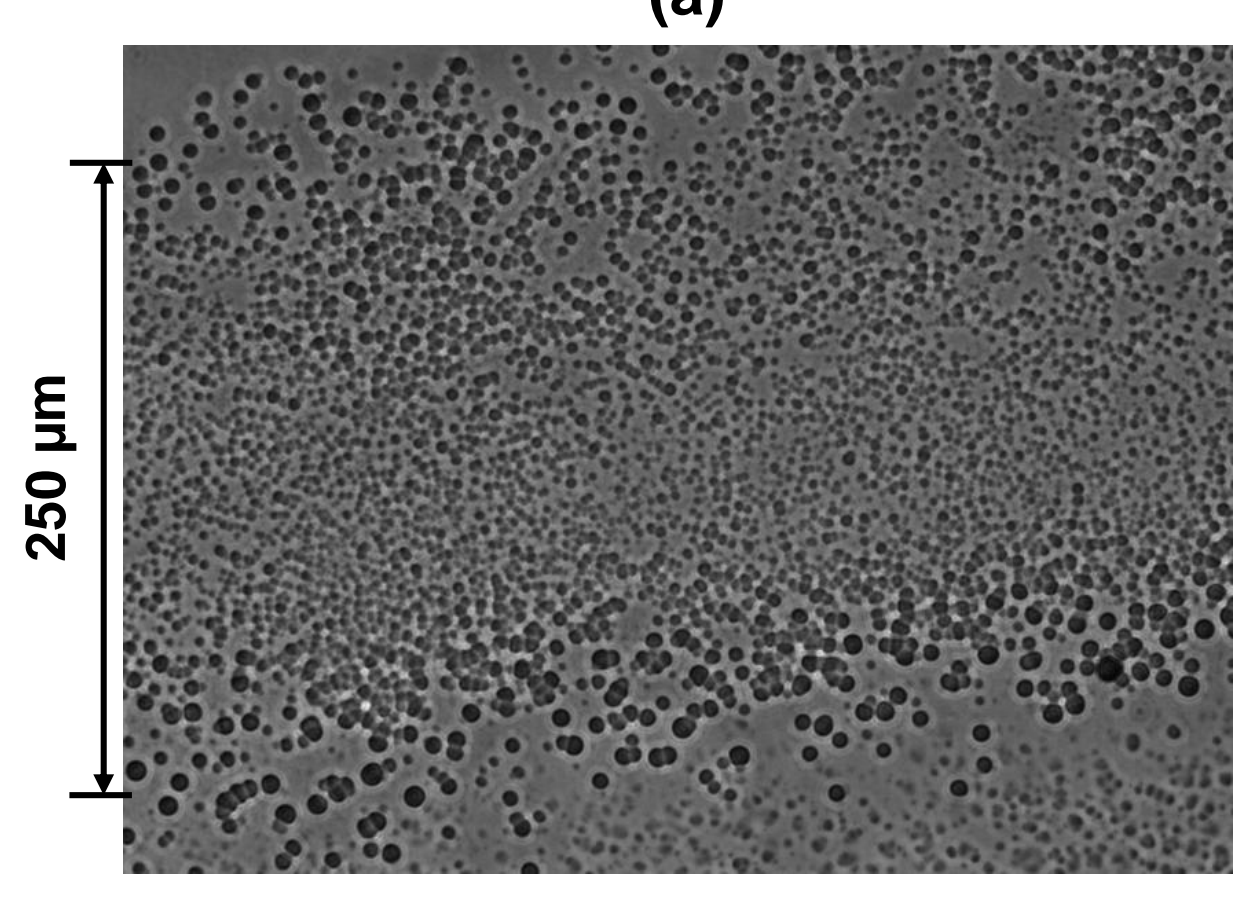

(b)

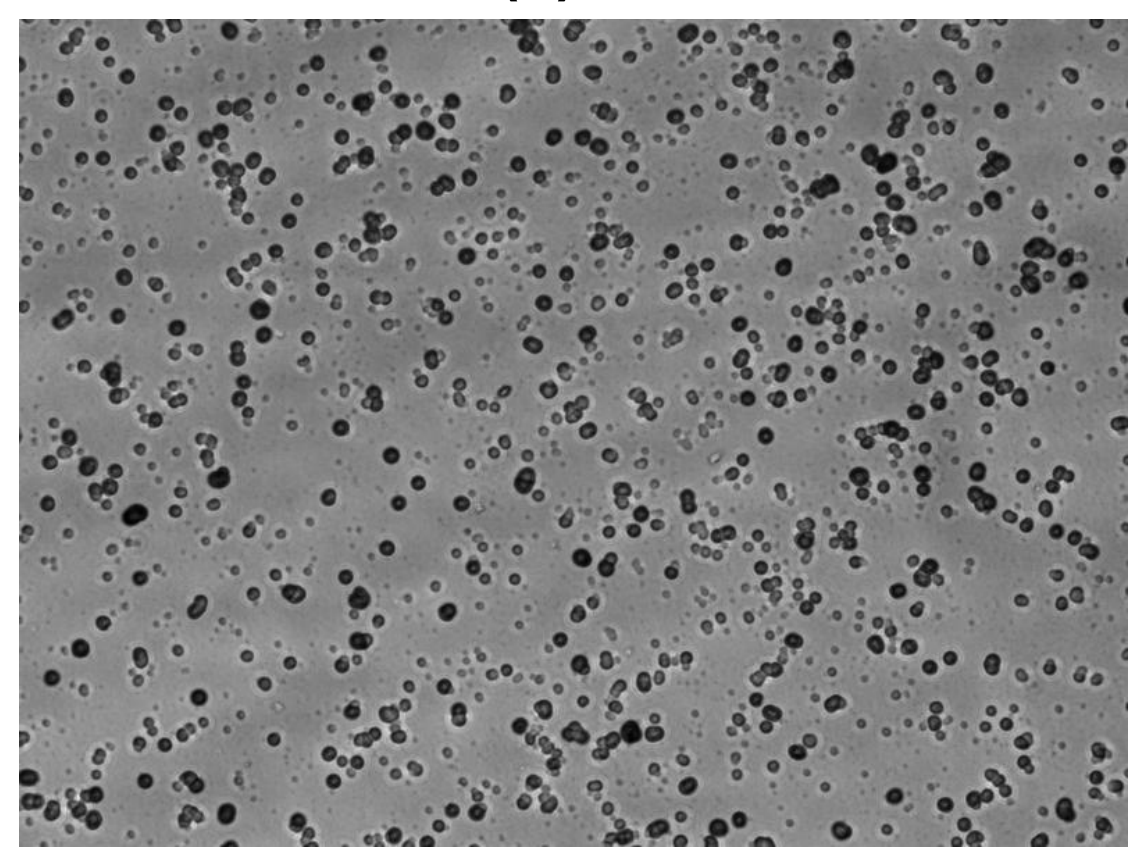


(a)

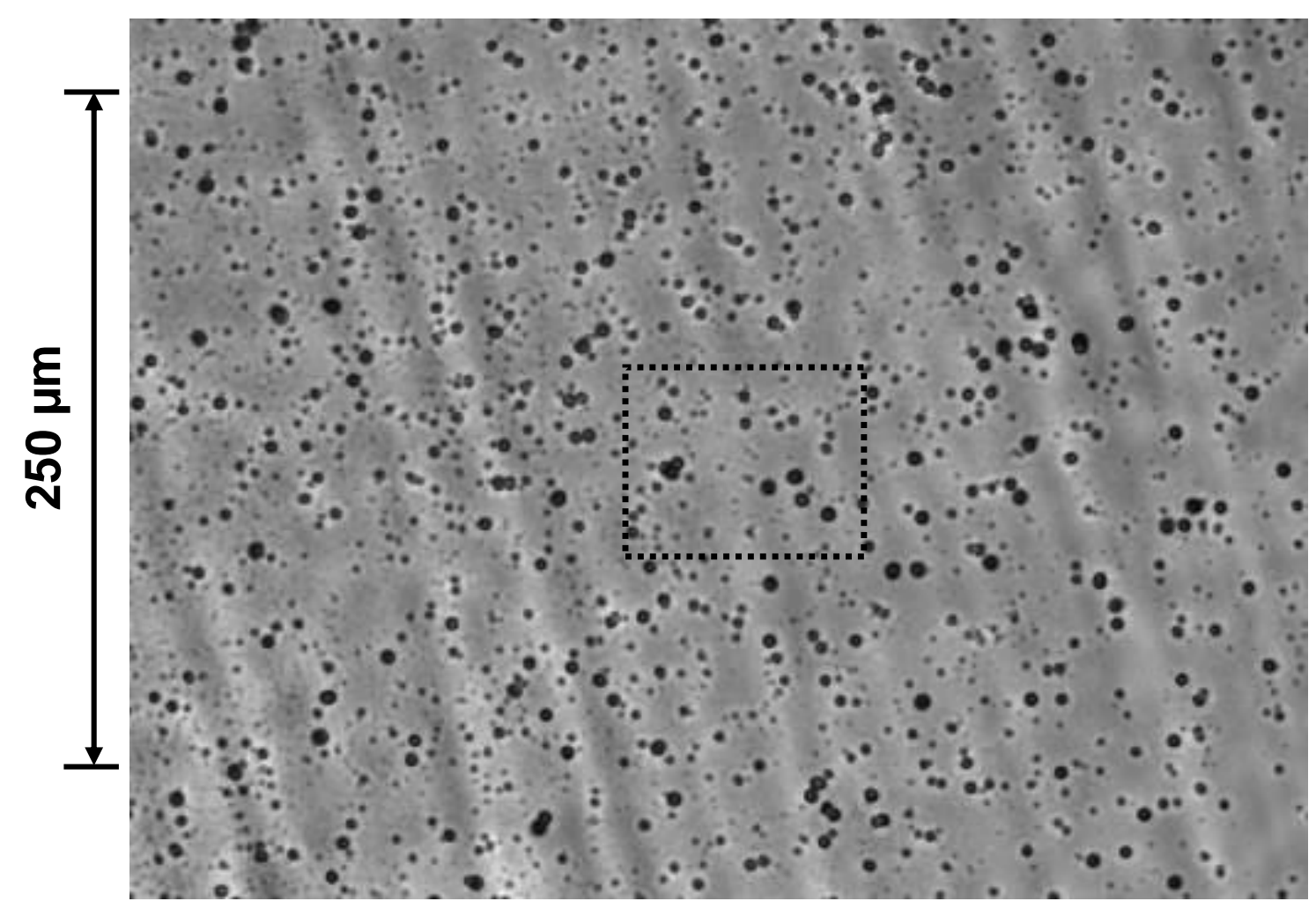

(b)

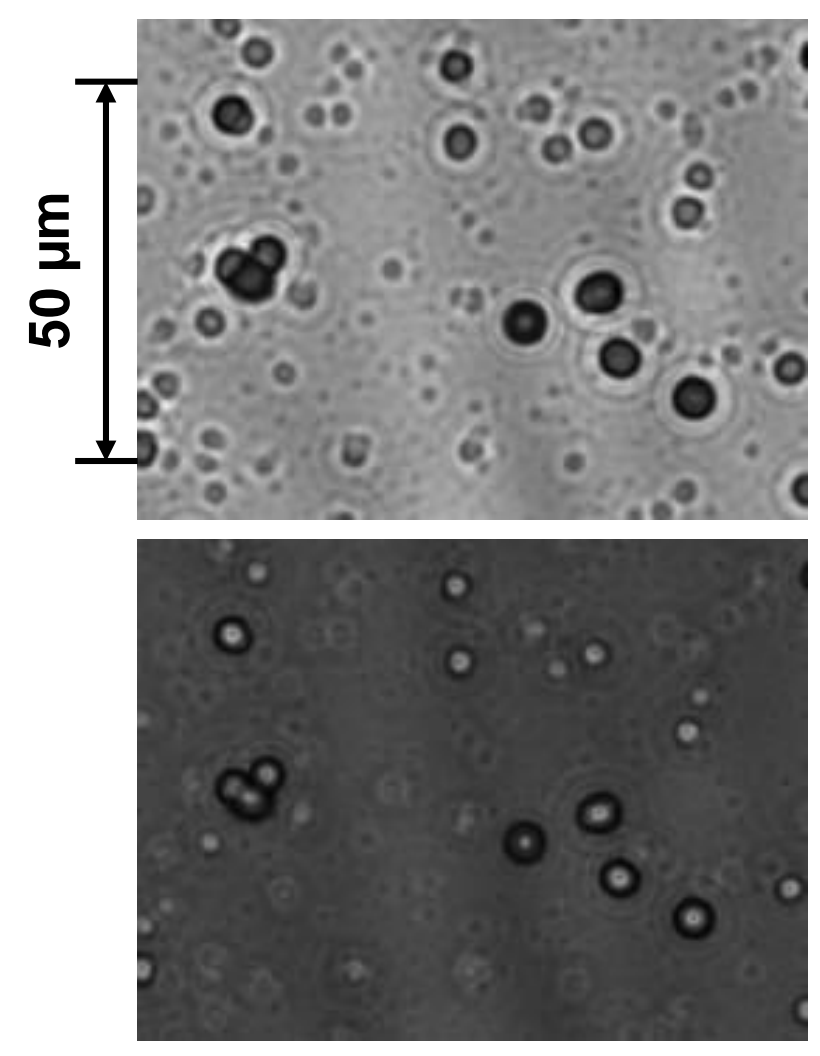


Figure 4

(a)

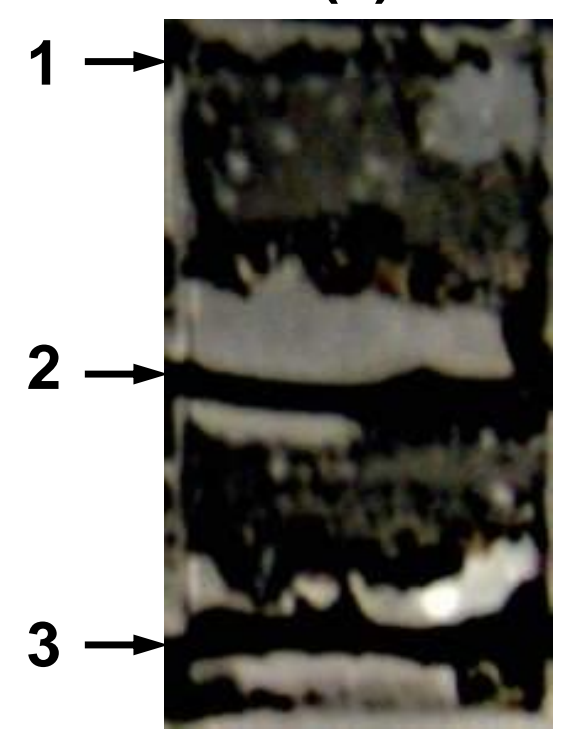

(c)

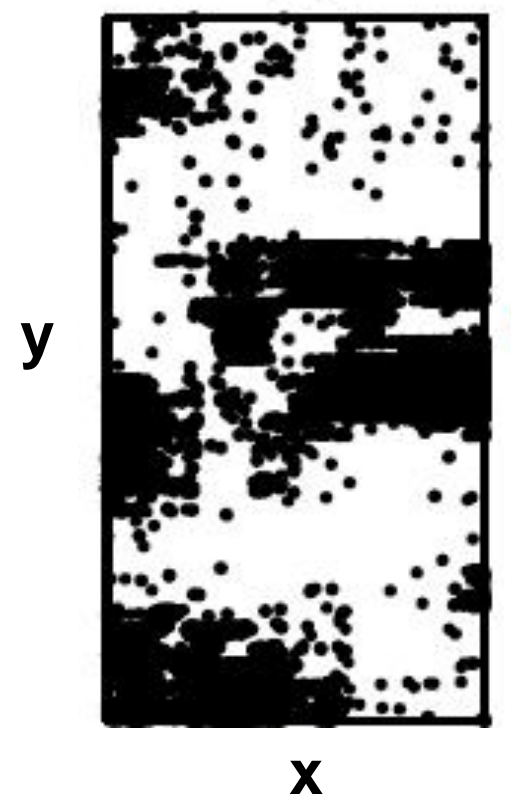

(b)

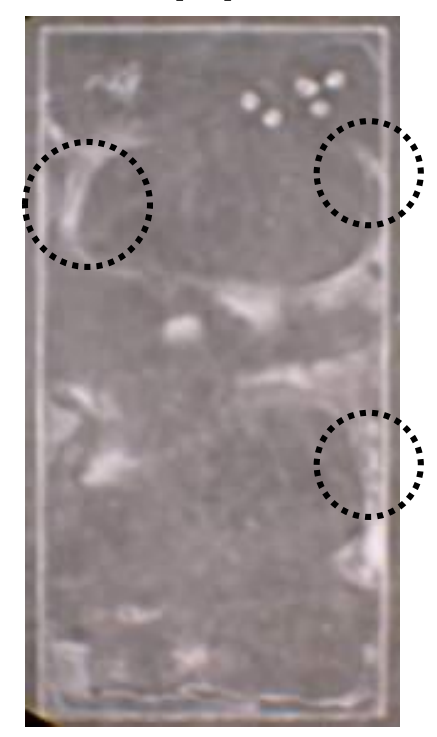

(d)

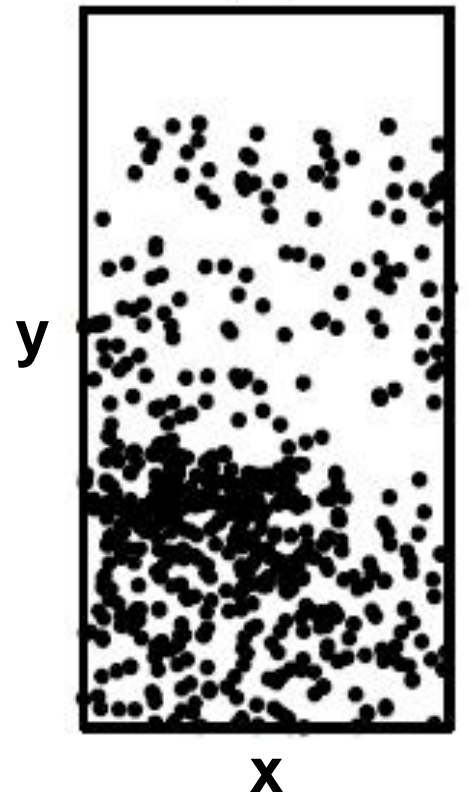




\section{Figure 5}

(a)

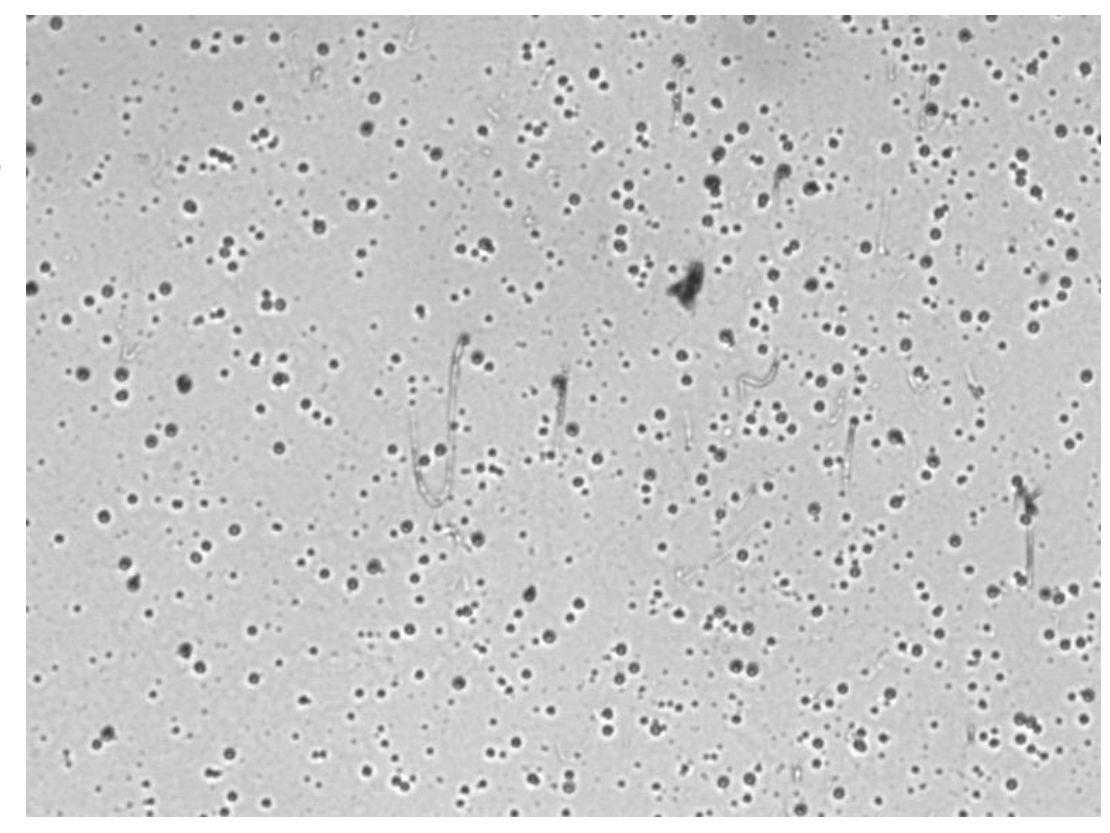

(b)

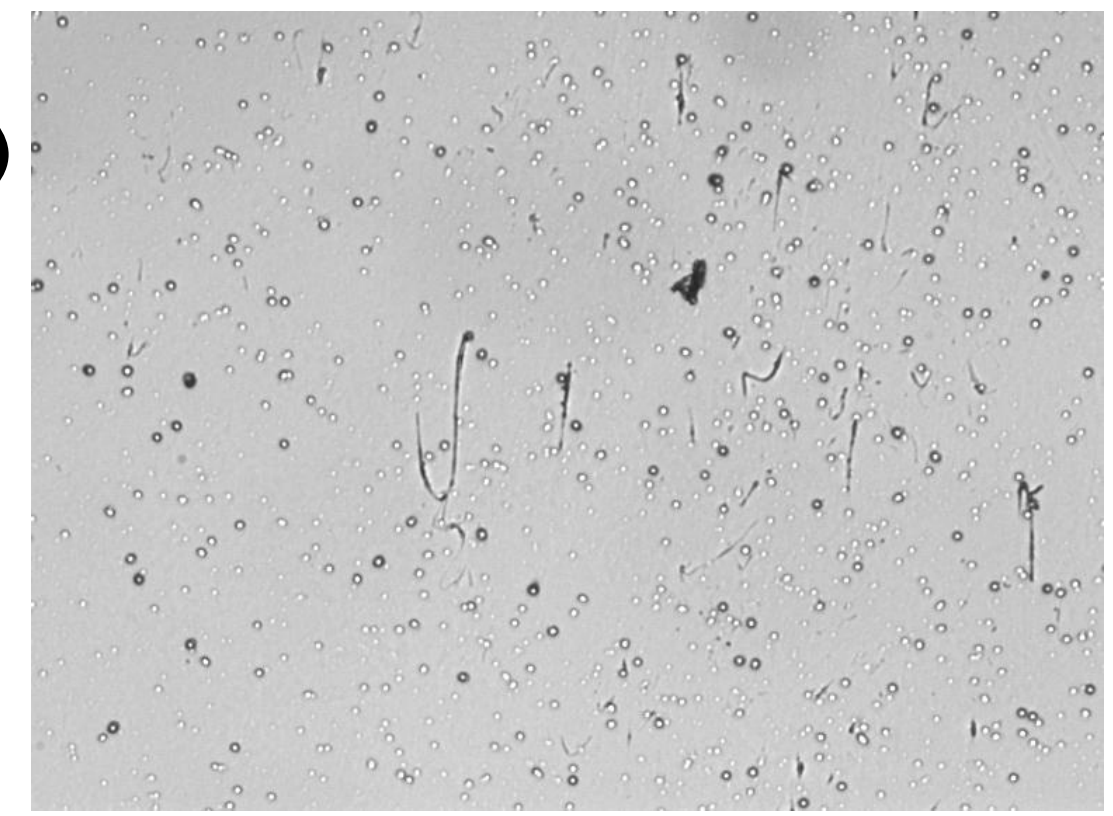

(c)

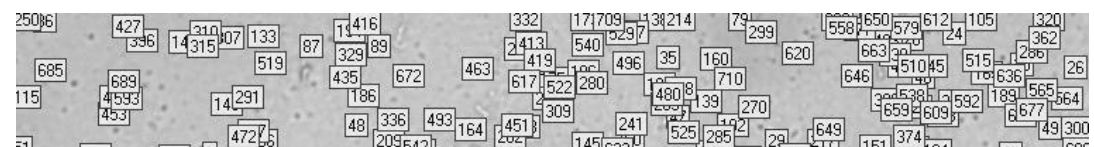

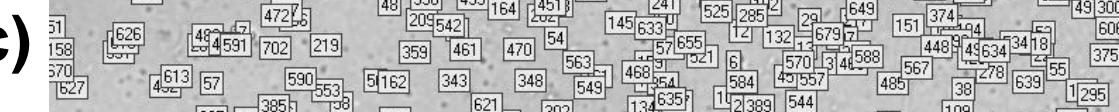

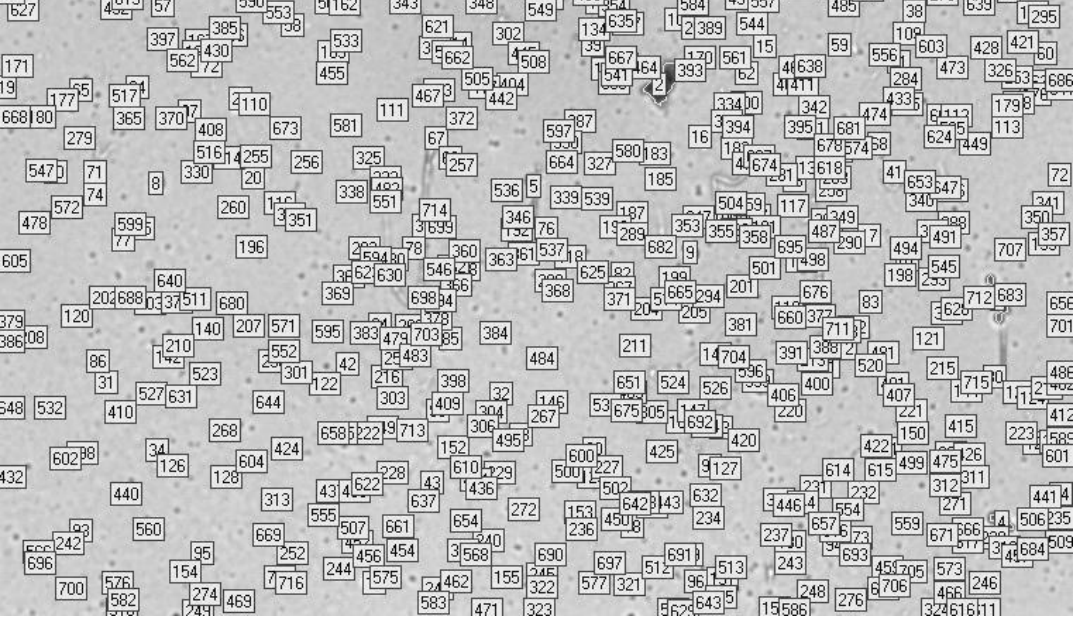

(d)

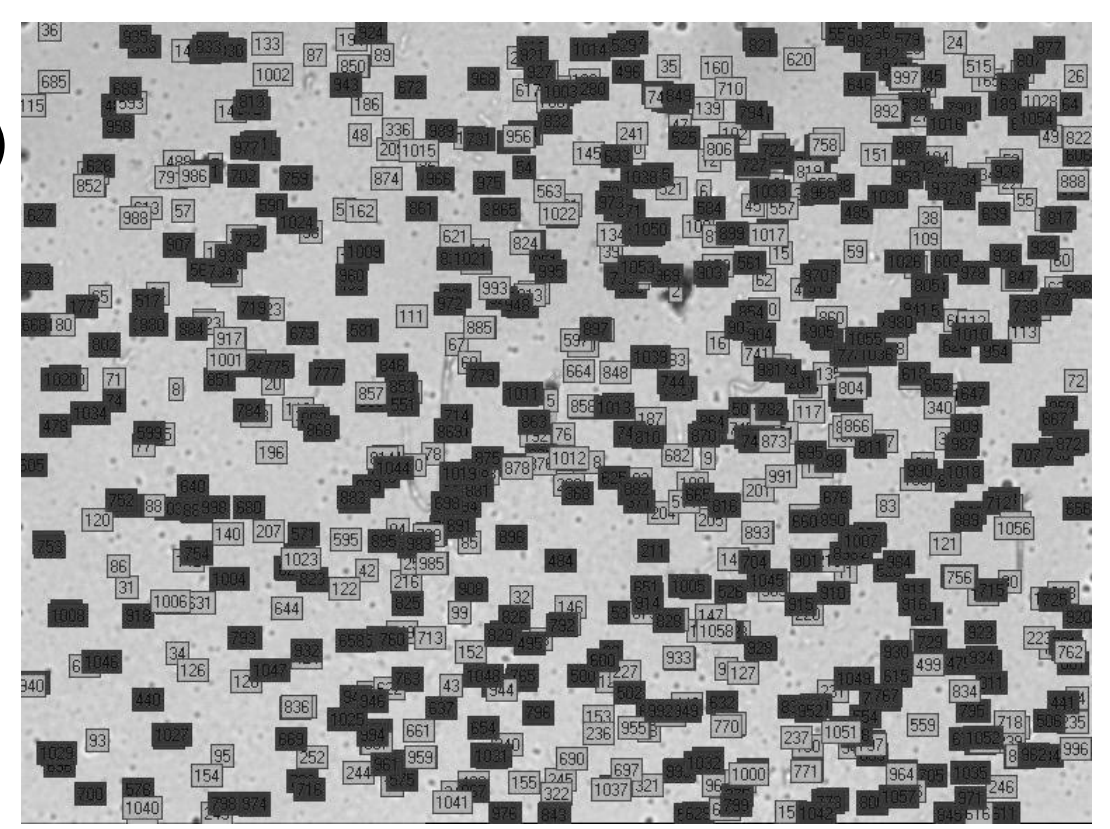


Figure 6
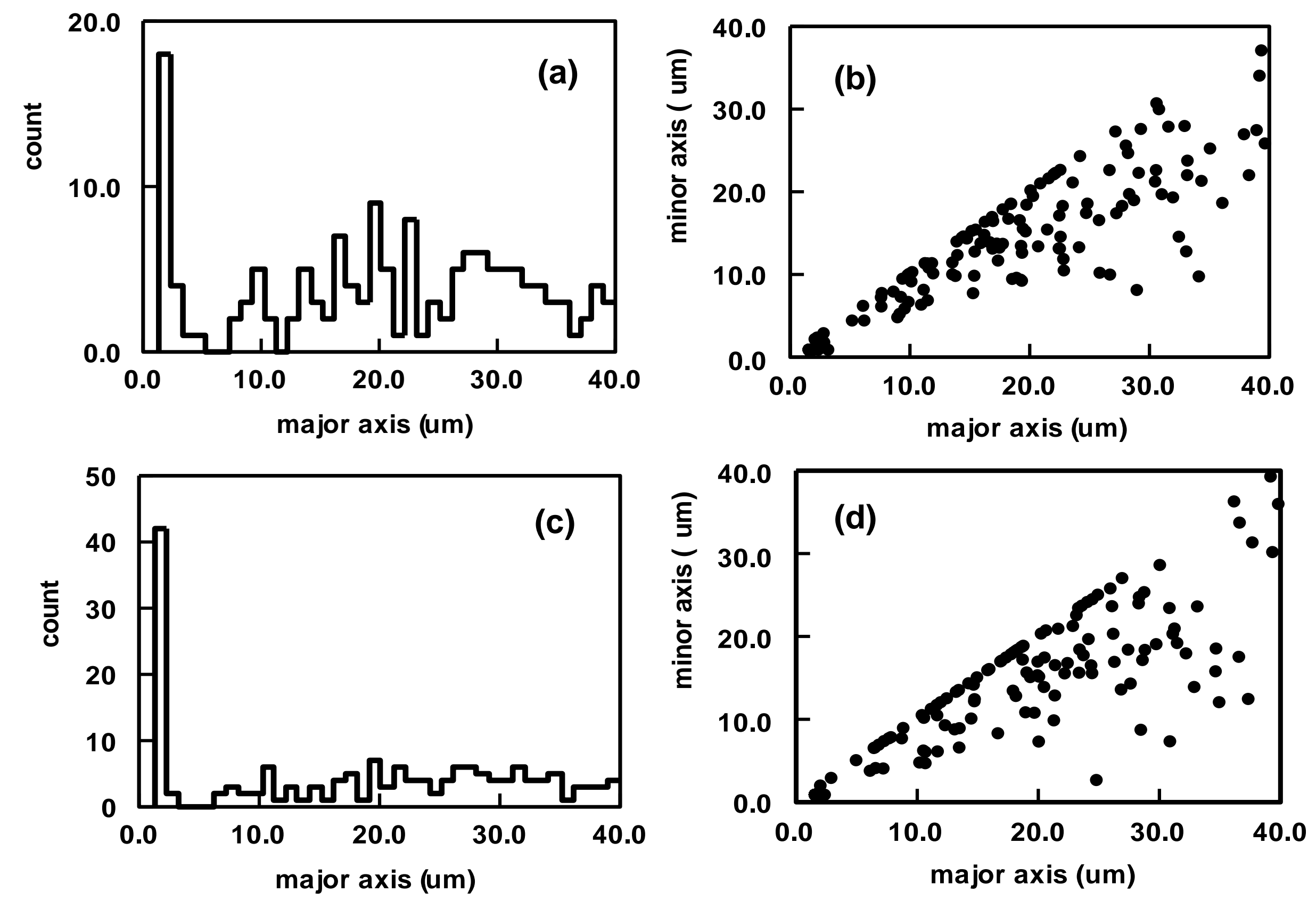
Figure 7
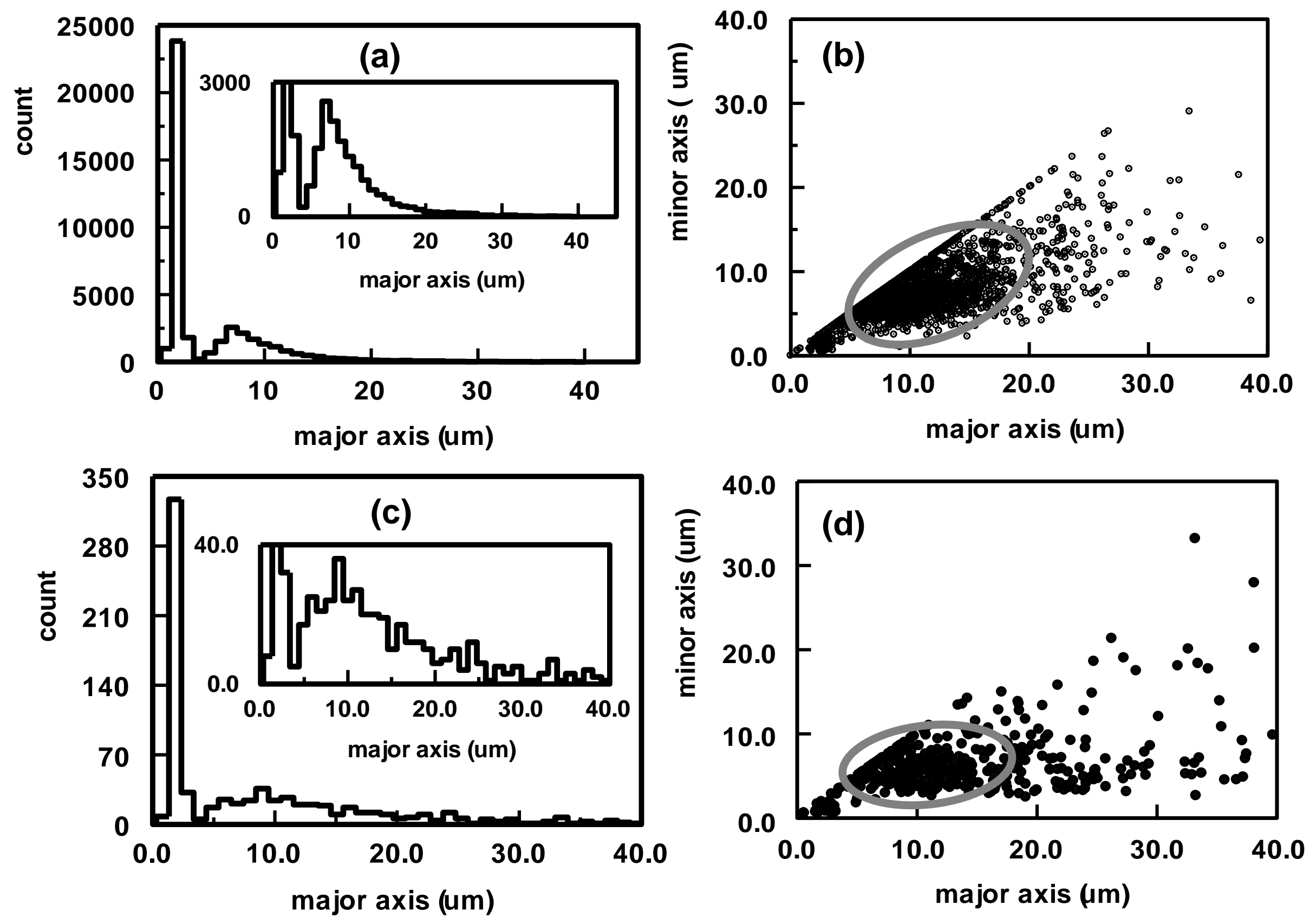
CATHODE SIDE

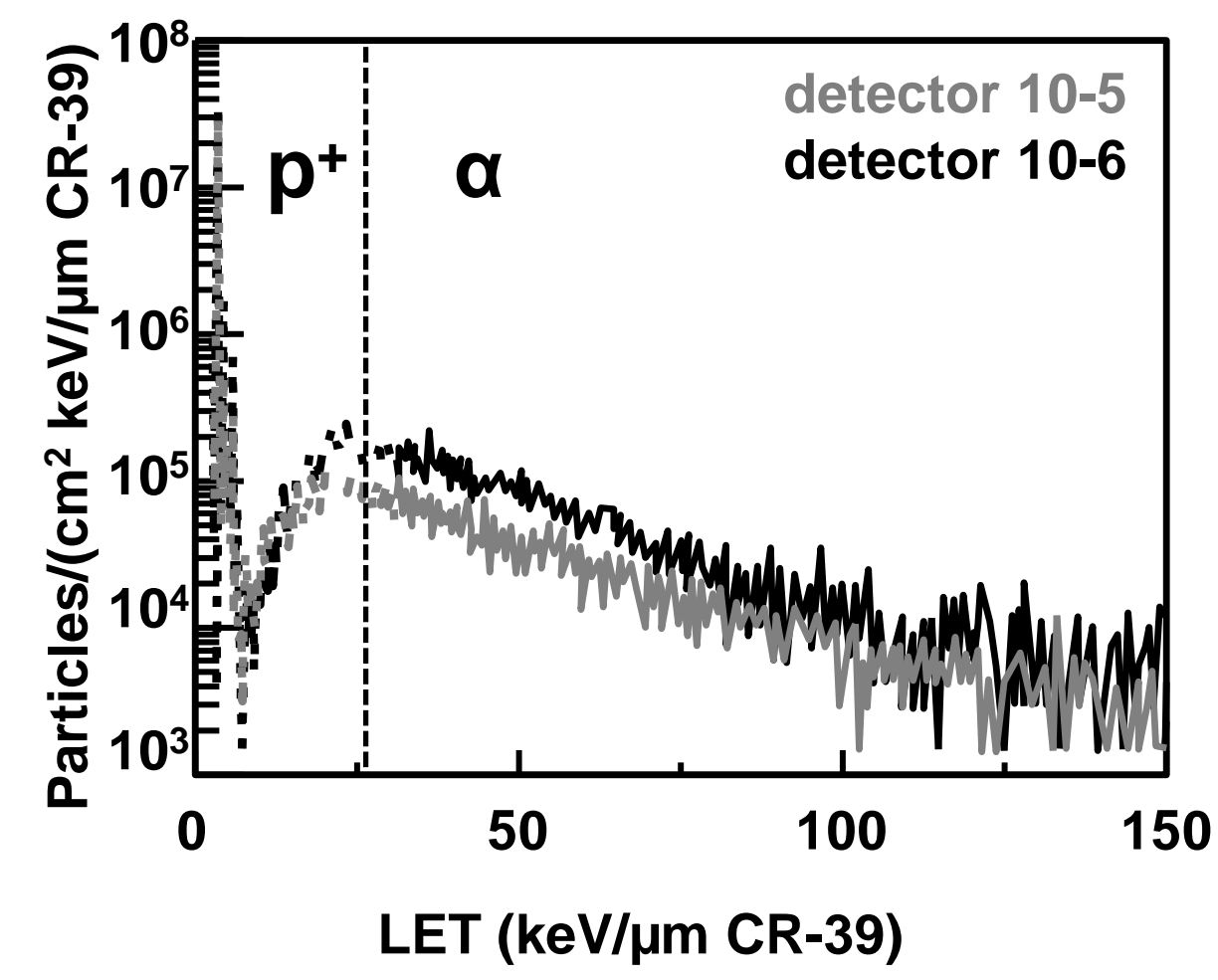

OBVERSE SIDE

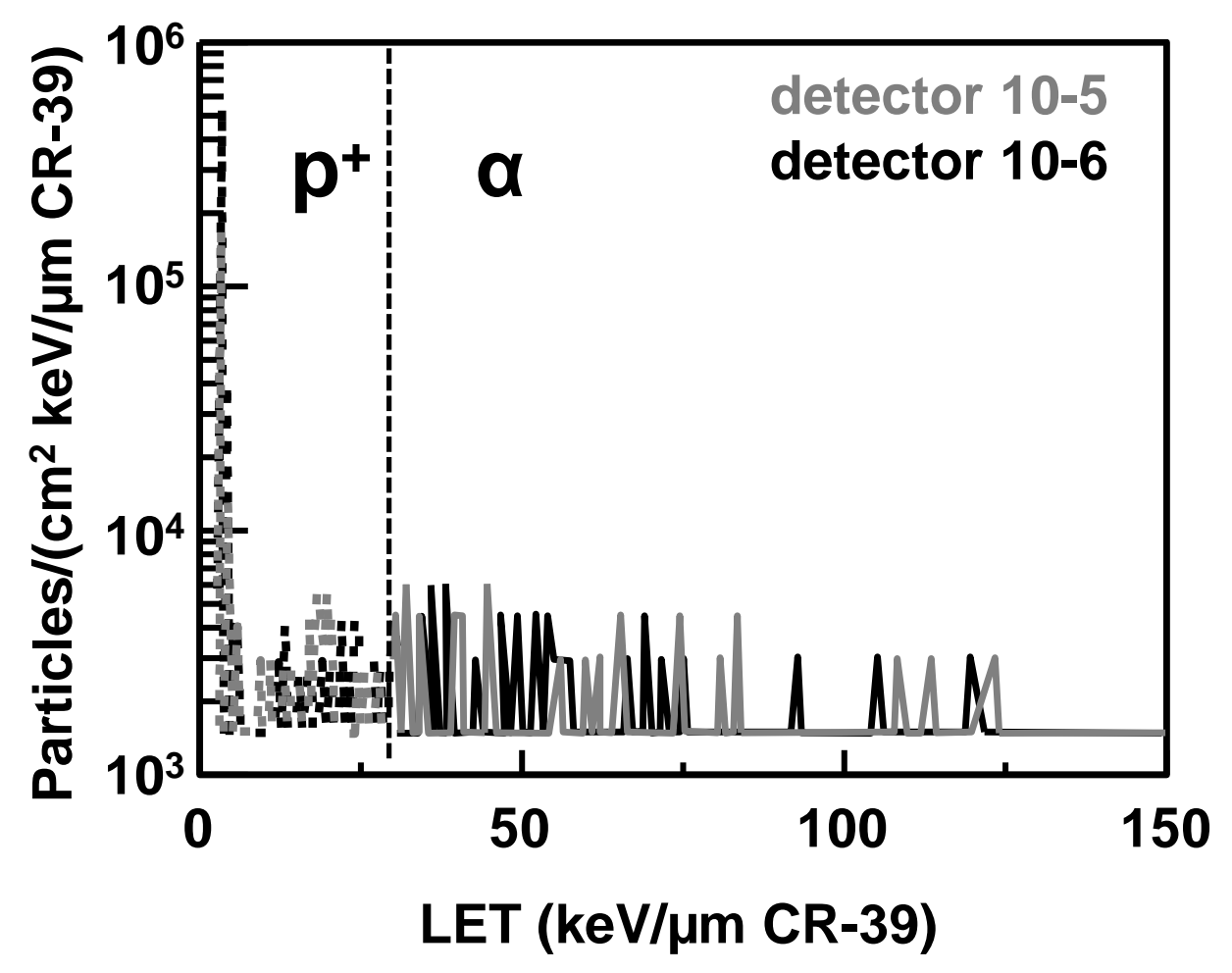



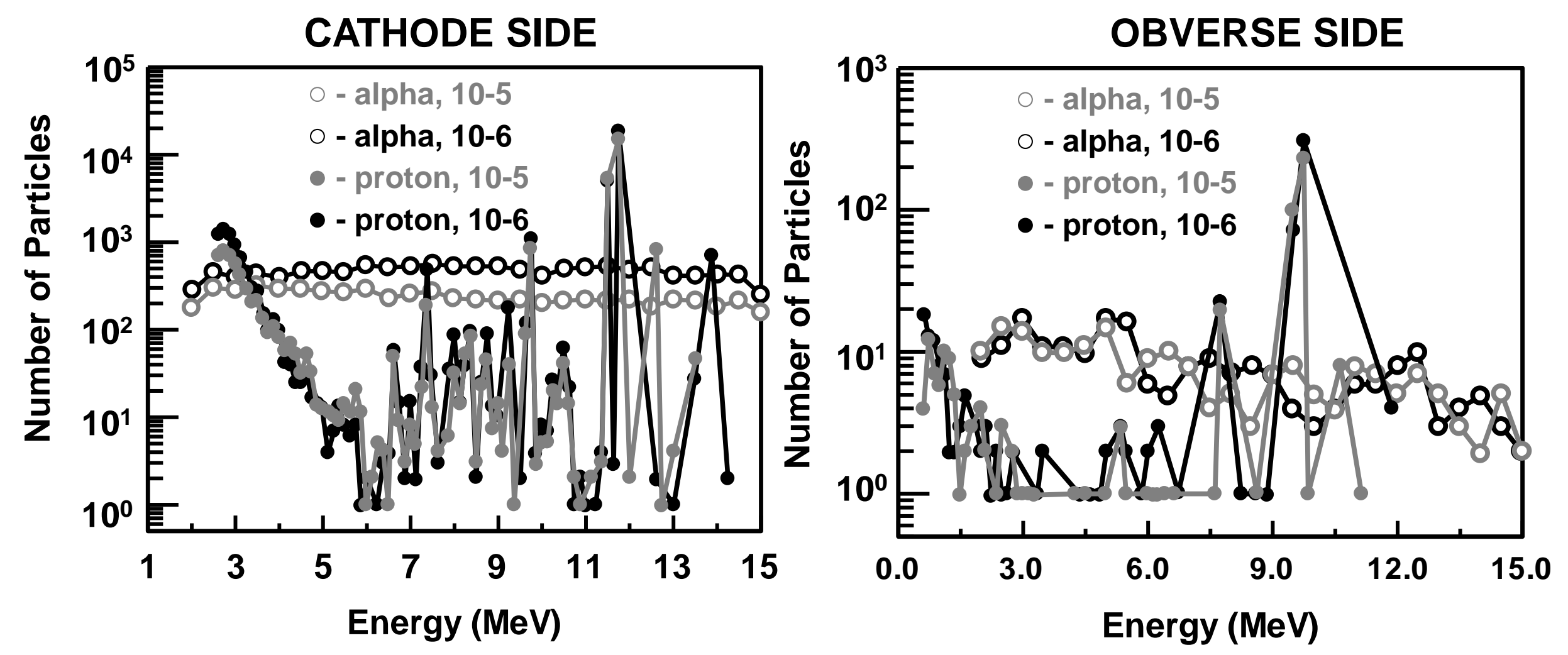

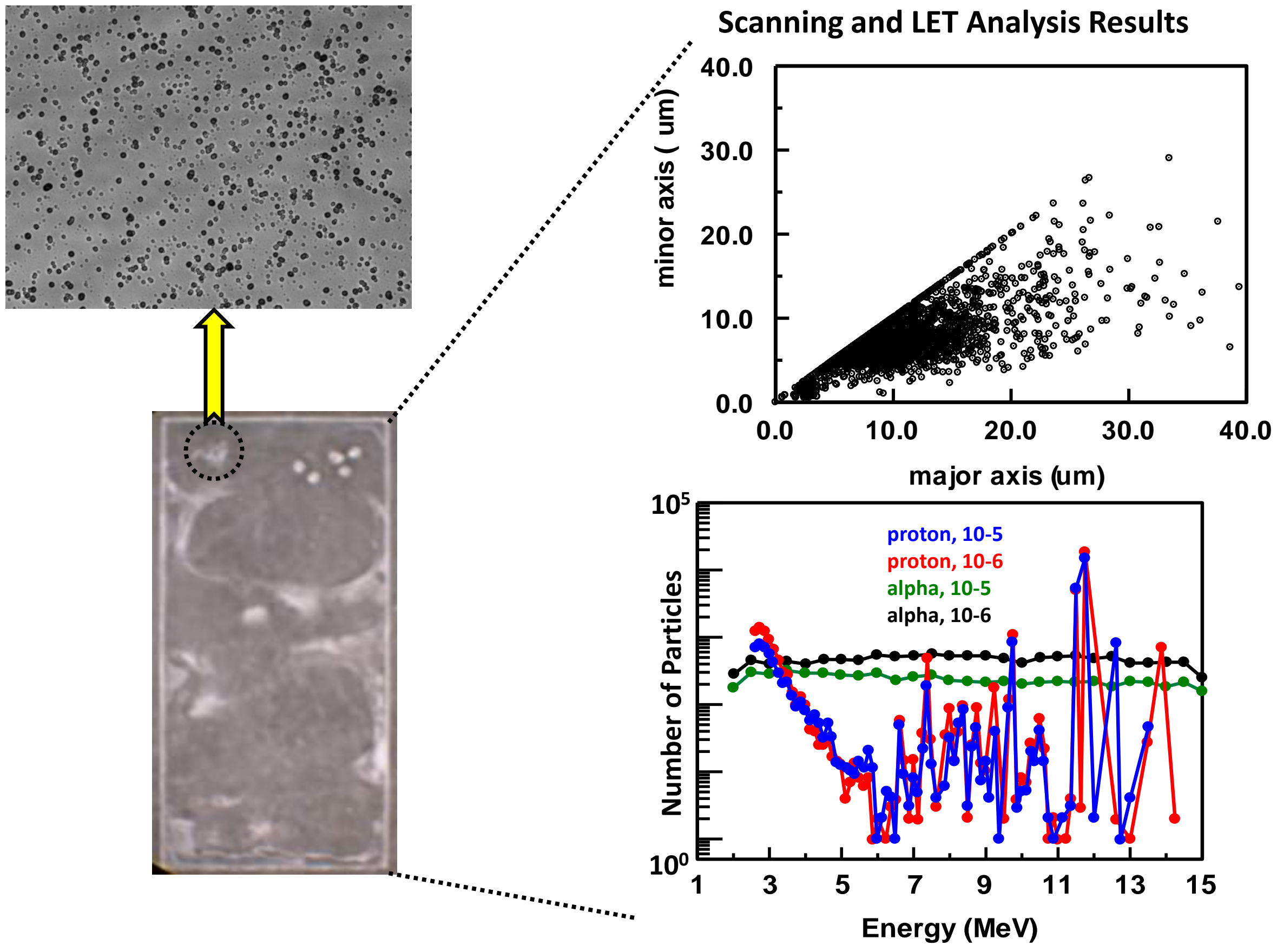